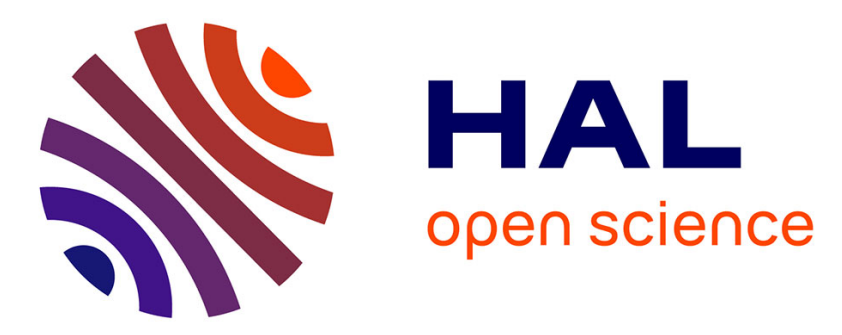

\title{
Tertiary Enamides as Versatile and Valuable Substrates to Reach Chemical Diversity
}

Frederic Beltran, Laurence Miesch

\section{To cite this version:}

Frederic Beltran, Laurence Miesch. Tertiary Enamides as Versatile and Valuable Substrates to Reach Chemical Diversity. Synthesis: Journal of Synthetic Organic Chemistry, 2020, 52 (17), pp.2497-2511. 10.1055/s-0040-1707403 . hal-02929890

\section{HAL Id: hal-02929890 \\ https://hal.science/hal-02929890}

Submitted on 20 Nov 2020

HAL is a multi-disciplinary open access archive for the deposit and dissemination of scientific research documents, whether they are published or not. The documents may come from teaching and research institutions in France or abroad, or from public or private research centers.
L'archive ouverte pluridisciplinaire HAL, est destinée au dépôt et à la diffusion de documents scientifiques de niveau recherche, publiés ou non, émanant des établissements d'enseignement et de recherche français ou étrangers, des laboratoires publics ou privés.

\section{다)(1) $(5$}

Distributed under a Creative Commons Attribution - NonCommercial| 4.0 International 


\section{Tertiary Enamides as Versatile and Valuable Substrates to Reach Chemical Diversity}

\author{
Frédéric Beltran ${ }^{\mathrm{a}}$ \\ Laurence Miesch*b \\ a Institute of Organic Chemistry, RWTH Aachen University, \\ Landoltweg 1, 52074 Aachen (Germany). \\ ${ }^{\mathrm{b}}$ Équipe Synthèse Organique et Phytochimie, Institut de \\ Chimie, CNRS-UdS UMR 7177, 4, rue Blaise Pascal CS 90032, \\ 67081 Strasbourg (France). \\ Imiesch@unistra.fr
}

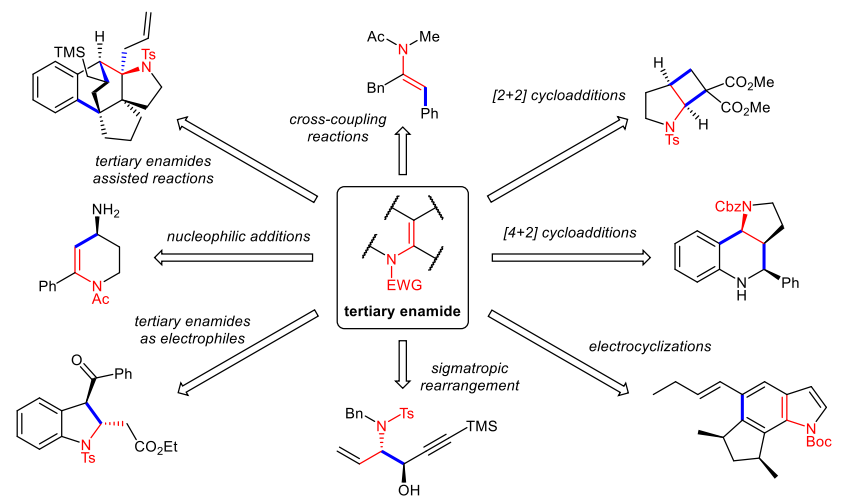

Consequently, tertiary amides have gained considerable attention over the past few years. This fact has been emphasized in several reviews. In 2014, Gillaizeau and coworkers summarized the reactivity of enamides toward direct metal-catalyzed functionalization, notably palladium cross coupling reactions. ${ }^{2}$ Shortly afterward, Wang concentrated on the recent advances regarding the nucleophilic reactions of tertiary enamides involving a wide range of electrophiles. ${ }^{3}$ Most recently, Cai, Guo, and co-workers resumed the achievements of the past decade, reporting the synthesis and reactivity of tertiary enamides involving principally coupling reactions, functionalization reactions, and electro- and photochemical reactions. ${ }^{4}$

In this context, with due respect to the previously published accounts, the aim of this short review is to complement the previous ones by focusing exclusively on tertiary enamides. Therefore, the reactivity of tertiary enamides will be correlatively covered from the seminal contributions to the most recent developments according to different reaction types. It should also be pointed out that this review does not pretend to be exhaustive and only highlights a limited number of papers deemed by the authors to be most representative. We will mostly cover pericyclic reactions, electrocyclizations, rearrangements, as well as the recent progress regarding nucleophilic additions, cross coupling reactions and finally tertiary enamides assisted reactions.

\section{$2 \quad[2+2]$ Cycloadditions}

In 1993, Correia and co-workers developed a [2+2] cycloaddition between endocyclic enamides or enecarbamates 1 and ketenes generated in situ by treatment of the corresponding acid chlorides 2 with triethylamine. 5 The [2+2] cycloaddition reaction affords azabicyclic cyclobutanones $\mathbf{3}$ in moderate to good yields (Scheme 1). It is interesting to note that only one 
regioisomer is produced in the process. In some instances, azabicyclic cyclobutenes $\mathbf{4}$ are obtained when enecarbamates $\mathbf{1}$ are employed instead of enamides (Scheme 1). These compounds possibly resulted from the enolization of the aza-alkoxycyclobutanone 3 followed by an $O$-acylation by the alkoxy-ketene. To highlight this method, the authors also reported the synthesis of the Geissman-Waiss lactone $\mathbf{5}$ using their [2+2] cycloaddition reaction (Scheme 1).

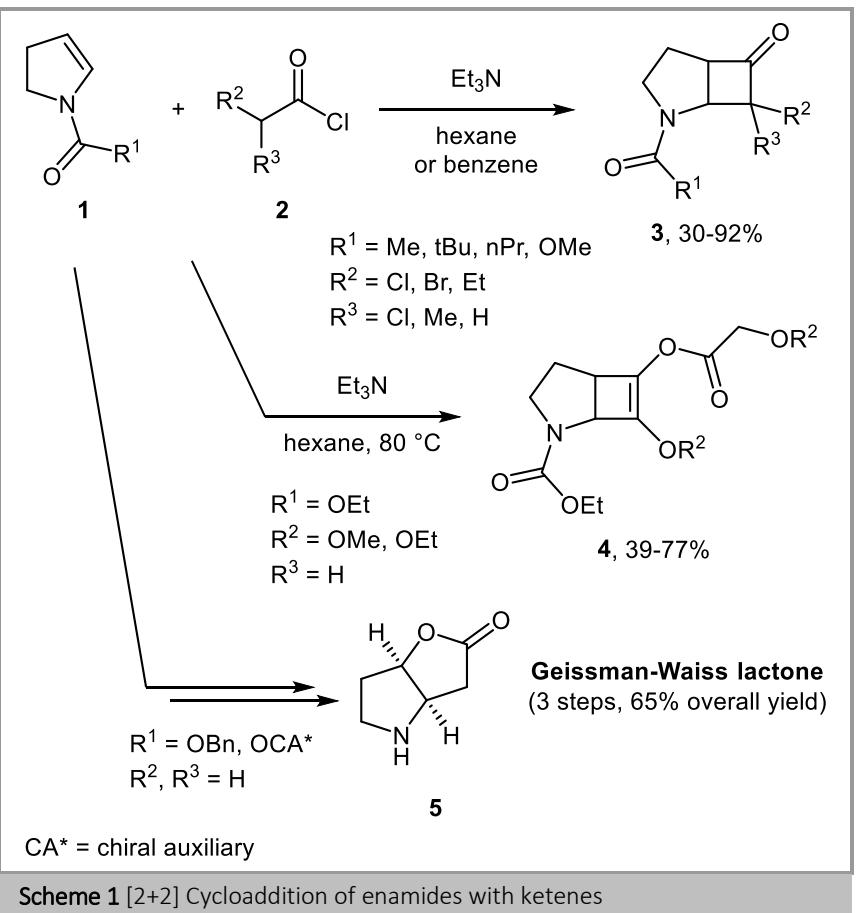

Two years later, these authors reported the synthesis of indolizidine and pyrrolizidine alkaloids using the previously described cycloaddition reaction between enecarbamates and alkyl-ketenes. ${ }^{6}$ They further examined the diastereofacial selectivity of enecarbamates bearing a chiral auxiliary (CA*) 1 toward the $[2+2]$ cycloaddition with dichloro-ketenes. ${ }^{7}$ Despite the low diastereoselectivity, a new enantioselective route to the Geissman-Waiss lactone 5 was achieved (Scheme 1).

Most recently, Smith and co-workers reported the synthesis of fused indoline-cyclobutanone derivatives 7 using a [2+2] cycloaddition method with enesulfonamides 6 and ketenes generated in situ. ${ }^{8}$ The synthesis of indoline-cyclobutanone fused products 7 starting from enesulfonamides $\mathbf{6}$ was achieved by treatment with pivaloyl chloride and iPrNEt 2 in $\mathrm{CHCl}_{3}$ at room temperature (Scheme 2). It is worth noting that only the $(E)$ enesulfonamide 6 was involved in the transformation: the $(Z)$ enesulfonamide 6 appears to isomerize or degrade under the reaction conditions, thus explaining the moderate yields observed.

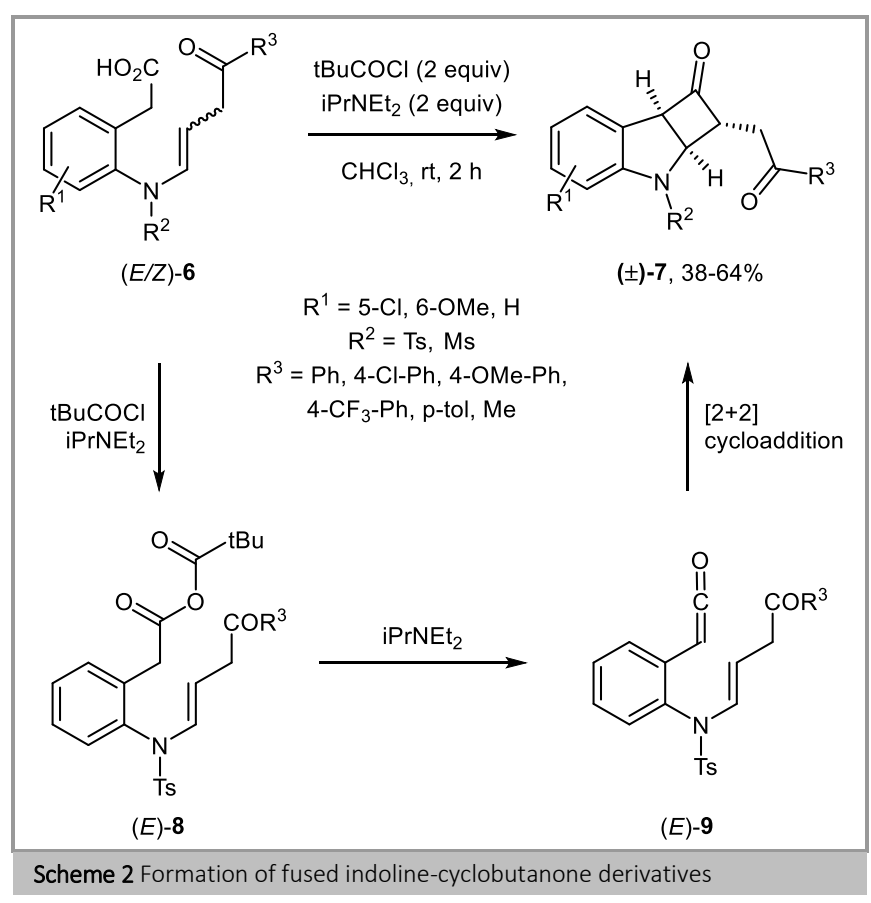

On the basis of additional studies, the authors suggested that the enesulfonamide $\mathbf{6}$ may react with pivaloyl chloride and Hünig's base to provide access to a mixed anhydride $\mathbf{8}$, which can be converted into ketene 9 by treatment with a second equivalent of base. Subsequently, an intramolecular [2+2] cycloaddition between the ketene and the enesulfonamide moieties affords the fused indoline-cyclobutanone products $\mathbf{7}$ as a diastereoisomer (Scheme 2).

In 2009, Hsung and co-workers examined the reactivity of tertiary enamides with arynes. Because benzyne can be generated in situ from $o$-(trimethylsilyl)benzyl triflate employing Kobayashi's mild fluoride-based conditions, ${ }^{9}$ it appears as a relevant partner for [2+2] cycloaddition reactions. In this context, Hsung and his group studied not only the feasibility of a $[2+2]$ cycloaddition involving benzynes and enamides but also the possibility of a tandem [2+2] cycloaddition/pericyclic ringopening/intramolecular [4+2] cycloaddition. ${ }^{10}$

Using olefin-tethered enesulfonamides $\mathbf{1 2}$ and benzyne $\mathbf{1 1}$ as reaction partner, amido-benzocyclobutanes $\mathbf{1 3}$ were obtained upon [2+2] cycloaddition, and subsequent ring-opening/[4+2] Diels-Alder cycloaddition could be achieved, providing a straightforward access to aza-tricycles $\mathbf{1 5}$ in good to excellent yields and as single diastereoisomers (Scheme 3A).

This method could be extended to the total syntheses of benzophenanthridine alkaloids Chelidonine $\mathbf{1 7}$ and Norchelidonine 18 (Scheme 3B). ${ }^{11}$ 


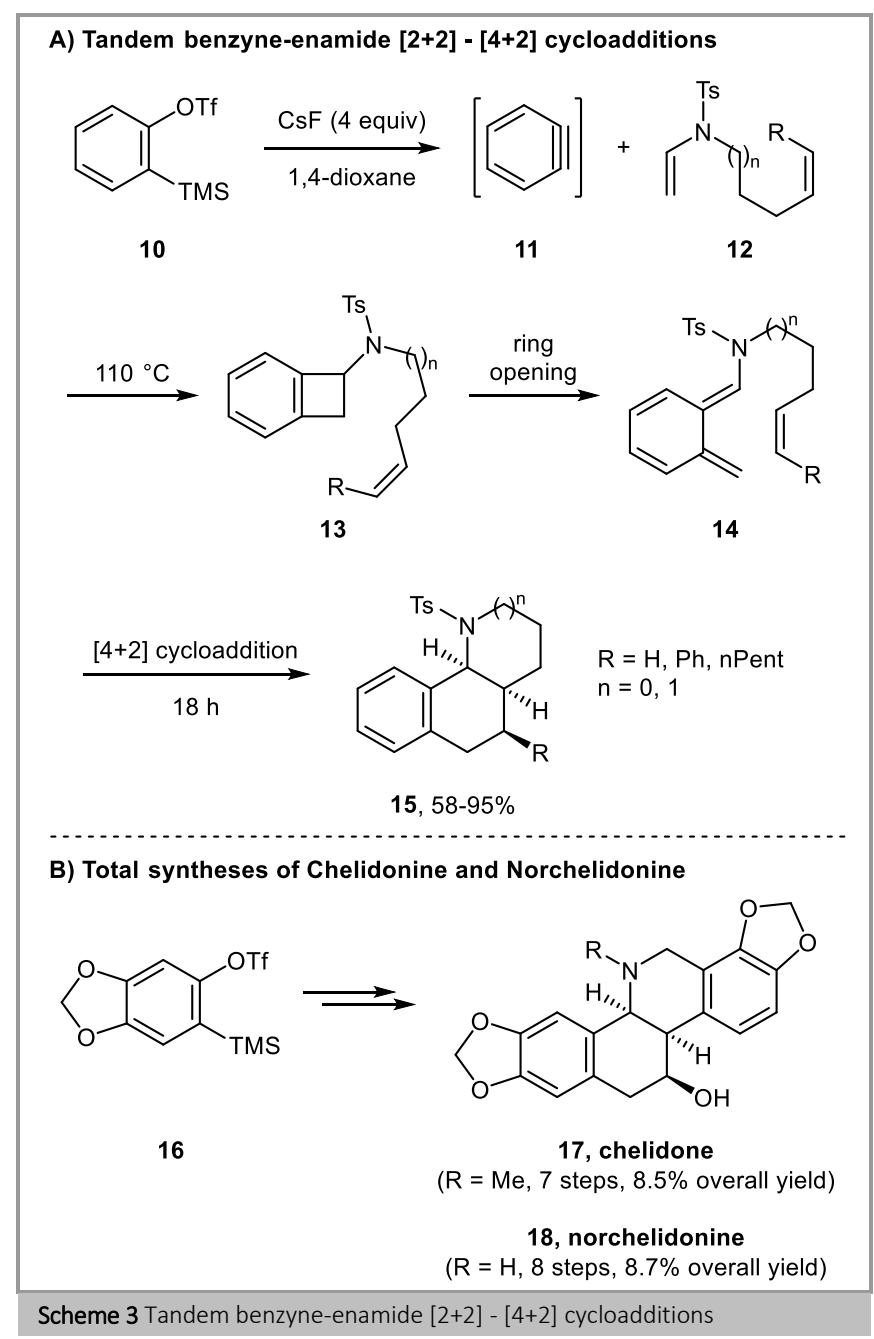

In 2013, an interesting strategy for the synthesis of aminocyclobutanes 21 that relies on iron-catalyzed [2+2] cycloaddition between enimides $\mathbf{1 9}$ and alkylidene malonates $\mathbf{2 0}$ was explored by Waser and co-workers. ${ }^{12}$ This method benefits from the use of an inexpensive and non-toxic iron catalyst supported on alumina. The synthesis of various $\beta$-amino acid cyclobutane derivatives $\mathbf{2 1}$ was achieved in good to excellent yields and with a good diastereomeric ratio (Scheme 4A).

\section{A) [2+2] cycloaddition between enimides and alkylidene malonates}

$\overbrace{R^{3}}^{R^{1}}$

19

$\mathrm{R}^{1}, \mathrm{R}^{2}=$ Phth, succinyl, maleimy

$\mathrm{R}^{3}=$ alkyl, cycloalkyl, aryl

$\mathrm{R}^{4}=\mathrm{OMe}, \mathrm{Ph} ; \mathrm{R}^{5}=\mathrm{H}, \mathrm{Me}, \mathrm{Cy}, \mathrm{CF}_{3}$
B) [2+2] cycloaddition via prior preparation of alkylidene malonates

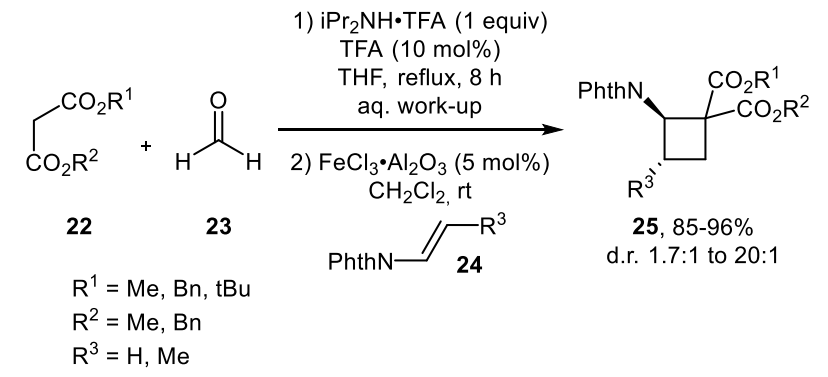

Scheme 4 Lewis acid catalyzed [2+2] cycloaddition between enimides and alkenes

Moreover, the authors extended their method to the synthesis of cyclobutanes $\mathbf{2 5}$ using a similar approach developed by Connell and co-workers ${ }^{13}$ for the preparation of highly reactive and unstable methylidene malonates. Mixing dicarbonyl compounds 22 and formaldehyde $\mathbf{2 3}$ with $\mathrm{PrNH}_{2}$ TFA and a catalytic amount of TFA afforded crude alkylidene malonate, which can be use without further purification. These alkylidene malonates reacted with enimides 24 and an iron catalyst, providing access to $\beta$ aminocyclobutanes 25 in good yields (Scheme 4B). It is worth noting that the synthesis of these cyclobutane derivatives was achieved on a gram-scale with only $5 \mathrm{~mol} \%$ of catalyst, demonstrating the efficiency of the method.

Most recently, Wang, Tang and co-workers published their research on a catalyst-controlled chemoselective $(2+2+2)$ and $(2+2)$ cycloadditions of enamides 26 with electron-deficient alkenes 27.14 The authors showed that the chemoselectivity of the reaction can be tamed depending on the choice of the catalyst. Indeed, the use of indium triflate controlled the reaction toward the formation of octahydroindoles 28 via $(2+2+2)$ cyclization in good to excellent yields (Scheme $5 \mathrm{~A}$ ). On the other hand, the use of copper triflate restrained the reactivity to a $(2+2)$ cycloaddition, affording cyclobutane derivatives $\mathbf{3 1}$ in good yields (Scheme 5B). It is worth noting that both reactions proceed with high diastereoselectivity in favor of the cis-diastereoisomer. 
A) $(2+2+2)$ cycloaddition<smiles>[R]C1=C([R])N([R16])[R]=CC1</smiles>

26

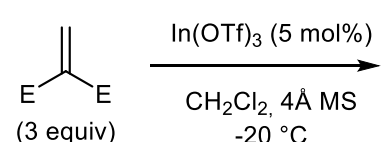

27

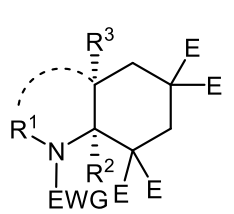

$28,55-93 \%$

$\mathrm{E}=\mathrm{CO}_{2} \mathrm{Me} ; \mathrm{EWG}=\mathrm{Ts}, p$-methoxybenzenesulfonyl $\mathrm{R}^{1}=\mathrm{Ph}, \mathrm{Bn},\left(\mathrm{CH}_{2}\right)_{2-4} ; \mathrm{R}^{2}=\mathrm{H} ; \mathrm{R}^{3}=\mathrm{H}, \mathrm{Me}, \mathrm{Pr}, \mathrm{Bn}$, allyl, propargyl, aryl

\section{B) $(2+2)$ cycloaddition}<smiles>[R]C1=CN([R16])[R1]=CC1</smiles>

29

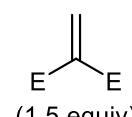

(1.5 equiv)

30
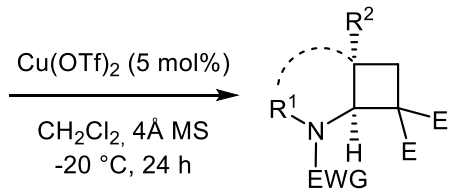

$31,56-92 \%$
$\mathrm{E}=\mathrm{CO}_{2} \mathrm{Me} ; \mathrm{EWG}=\mathrm{Ts}, p$-fluorotosyl

$\mathrm{R}^{1}=\mathrm{Bn},\left(\mathrm{CH}_{2}\right)_{2-3} ; \mathrm{R}^{2}=\mathrm{H}, \mathrm{Me}, \mathrm{Pr}, \mathrm{Bn}$, allyl, propargyl

C) Proposed mechanisms for the $(2+2+2)$ and $(2+2)$ cycloadditions<smiles>C=C(C(=O)OC)C(=O)OC</smiles>

32<smiles>[I-]N1C=CCC1</smiles>

33

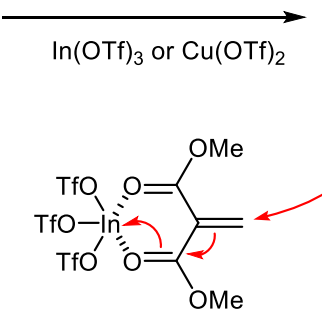

36

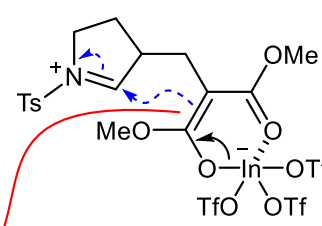

34

$\downarrow-\ln (\mathrm{OTf})_{3}$

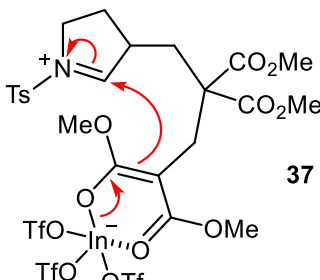
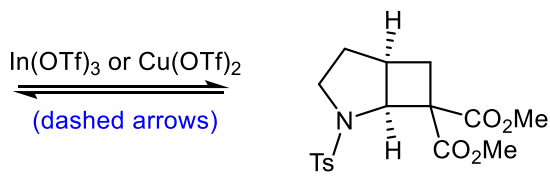

35
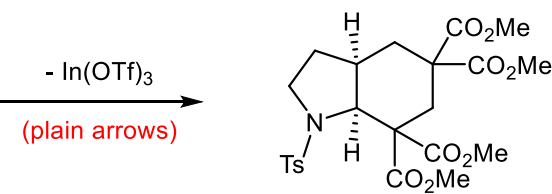

38

Scheme $5(2+2+2)$ and $(2+2)$ Cycloaddition between enamides and alkenes

A plausible mechanism for the $(2+2+2)$ and $(2+2)$ cyclizations is outlined in Scheme 5C. The authors presume that the process starts with the addition of the enesulfonamide $\mathbf{3 3}$ onto the dimethyl methylene malonate 32. Subsequently, the iminium intermediate $\mathbf{3 4}$ can be trapped intramolecularly to afford the cyclobutane derivative 35. Depending on the Lewis acid, the cyclobutane ring 35 can be subject to ring opening, and a nucleophilic addition of the zwitterionic 1,4 dipole intermediate $\mathbf{3 4}$ on a second molecule of dimethyl methylidene $\mathbf{3 6}$ can occur, leading to the formation of intermediate $\mathbf{3 7}$, which can further cyclize to afford $\mathbf{3 8 .}$

As an extension of their previous studies on $[2+2]$ photocycloadditions of enamines to aldehydes, ${ }^{15}$ in 2001, Bach and co-workers examined the synthesis of 3-aminooxetanes via a Paternò-Büchi reaction of enecarbamates and benzaldehyde. ${ }^{16}$ UV irradiation of enecarbamates 39 and benzaldehyde in acetonitrile led to the formation of 3-aminooxetanes $\mathbf{4 0}$ in good yields with high regioselectivity and as a cis:trans mixture (Scheme 6).

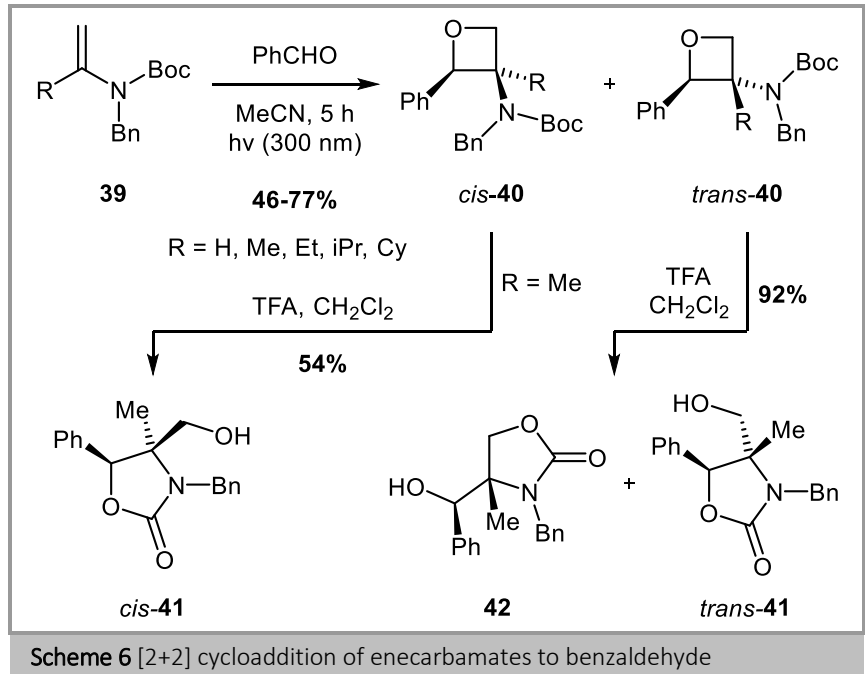

In the same paper the authors showed that 3-aminooxetanes $\mathbf{4 0}$ can be converted to oxazolidinones $\mathbf{4 1}$ or $\mathbf{4 2}$ by treatment with trifluoroacetic acid via an $\mathrm{S}_{\mathrm{N}} 2$-type process involving a ring opening followed by cyclization (Scheme 6).

In 2019, Elliott and Booker-Milburn reported an intramolecular [2+2] photocycloaddition of allyl-substituted tertiary enamides 43, providing access to 2,4methanopyrrolidine $\mathbf{4 4}$ in good to excellent yields with complete atom economy. ${ }^{17}$ This method relied on the use of an inexpensive 
organic triplet sensitizer (isopropylthioxanthone, ITX) as photocatalyst under UV light (Scheme 7). Under thermal conditions these bicyclic pyrrolidines $\mathbf{4 4}$ undergo fragmentation to cyclobutenes, with subsequent electrocyclic ring opening leading to dienes $\mathbf{4 5}$. The obtained dienes $\mathbf{4 5}$ then reacted - in a one-pot manner - with maleamic anhydride, affording bicyclic lactams 46 via a [4+2] cycloaddition/lactamization sequence (Scheme 7).

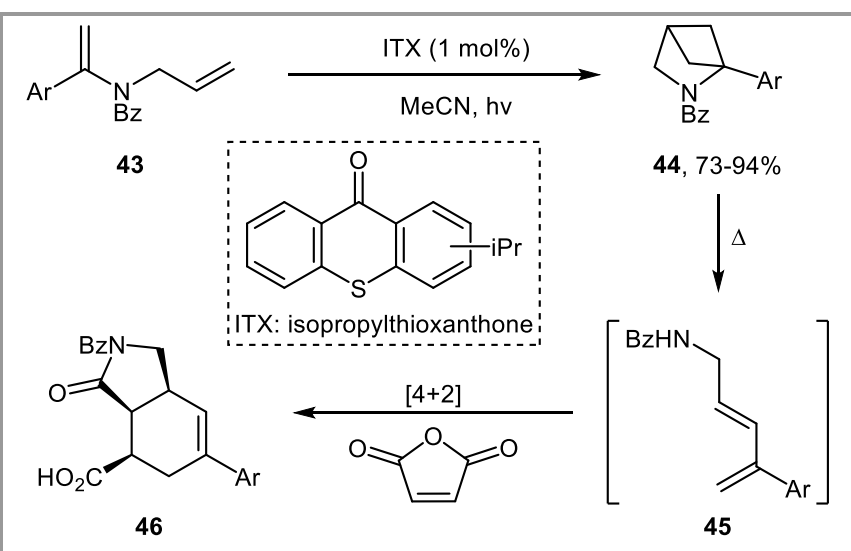

Scheme $7[2+2]$ photocycloaddition and subsequent cascade reactions

\section{$3 \quad[4+2]$ Cycloadditions}

In 2000, Rawal and co-workers reported an enantioselective [4+2] Diels-Alder cycloaddition reaction between enecarbamates 47 and acroleins 48 catalyzed by $\mathrm{Cr}$ Salen complexes 49.18 The Diels-Alder reaction was performed using $5 \mathrm{~mol} \%$ of Jacobsen's Cr-Salen catalyst $\mathbf{4 9}$ and provided only endo adducts $\mathbf{5 0}$ in good to excellent yields and with an enantiomeric excess up to $97 \%$ (Scheme 8).

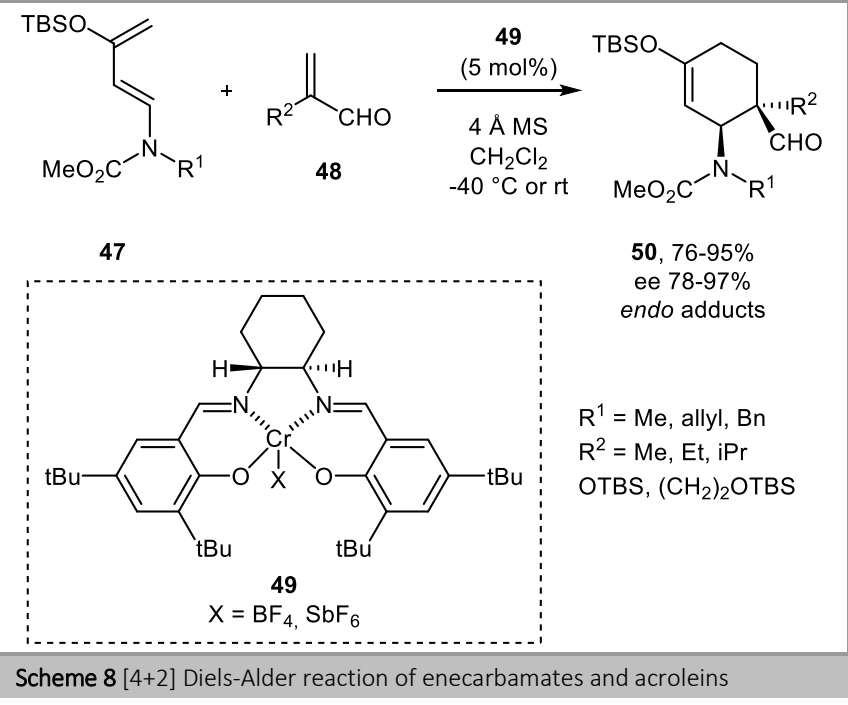

Later, in 2008, an interesting strategy for the synthesis of substituted piperidines $\mathbf{5 8}$ or tetrahydropyridines $\mathbf{5 5 , 5 9}$ that relies on a three-component [4+2] Diels-Alder reaction was explored by Nelson and co-workers. ${ }^{19} \mathrm{~N}$-Alkoxymethyl enesulfonamides $\mathbf{5 1}$ were used as convenient precursors to $\mathrm{N}$ alkenyl iminium ion dienes $\mathbf{5 2}$ by treatment with an equimolar amount of $\mathrm{TiCl}_{4}$ (Scheme 9). The diene 52 underwent [4+2] azaDiels-Alder cycloaddition with olefins $\mathbf{5 3}$ or $\mathbf{5 6}$, affording a tetrahydropyridinium ion intermediate 54, 57 with high exoselectivity. The former iminium ion intermediate was then trapped by an additional nucleophile or underwent $\mathrm{Et}_{3} \mathrm{~N}$ mediated deprotonation to afford substituted piperidines $\mathbf{5 8}$ or tetrahydropyridines $\mathbf{5 5}$ or $\mathbf{5 9}$ in good yields (Scheme 9).

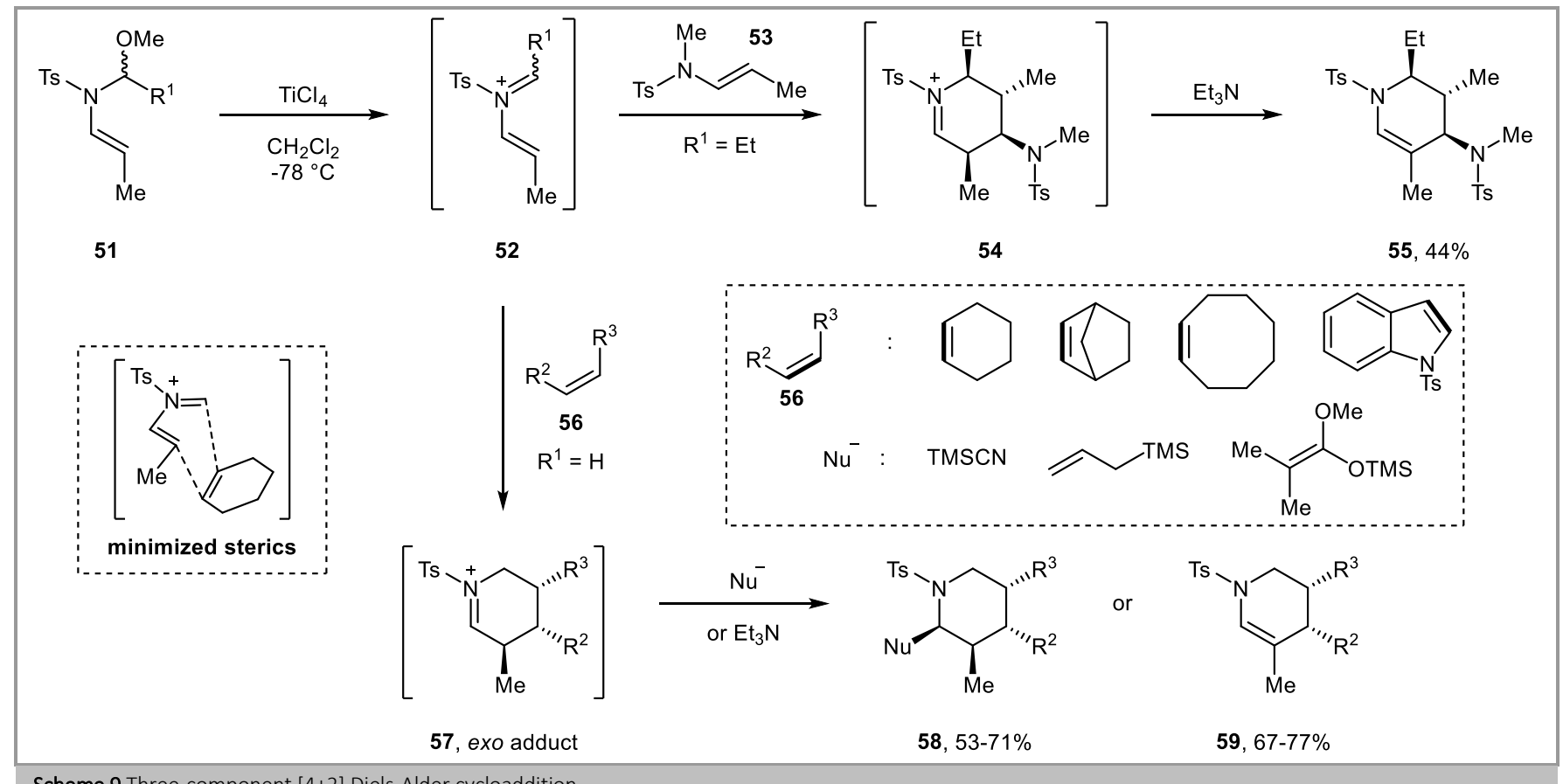


In 2014, Jha and co-workers published their research on the aza-Diels-Alder between $\mathrm{N}$-acyliminium ions and tertiary enamides. $^{20}$ The authors reported the synthesis of isoindoloquinoline derivatives $\mathbf{6 2}$ by reaction of $\mathrm{N}$-aryl-3hydroxyisoindolinones $\mathbf{6 0}$ and tertiary enamides $\mathbf{6 1}$ under anhydrous Lewis acid conditions using a stoichiometric amount of $\mathrm{BF}_{3} \bullet \mathrm{OEt}_{2}$ (Scheme 10A). It is interesting to note that only the endo cycloadducts were obtained during the reaction in modest to good yields.

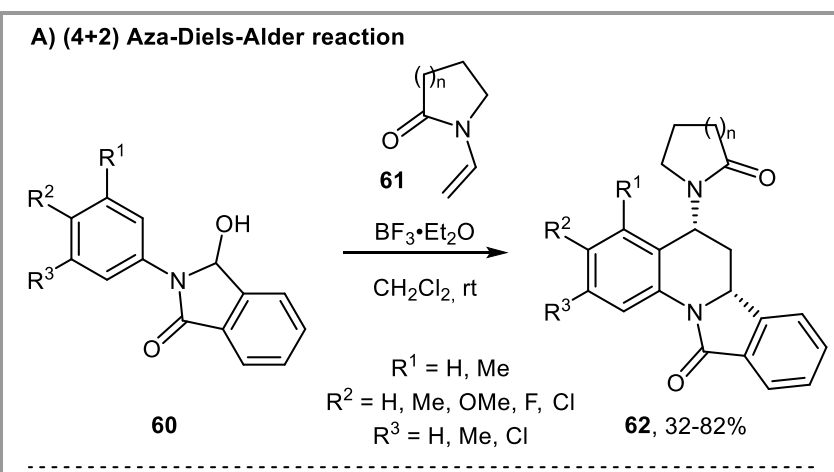

B) Enamide condensation to $\mathrm{N}$-acyliminium ion<smiles>[R]c1ccc([R])c(N2C(=O)c3ccccc3C2O)c1</smiles>

63

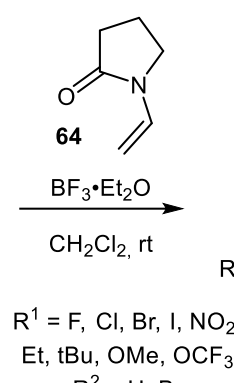

$\mathrm{R}^{2}=\mathrm{H}, \mathrm{Br}$

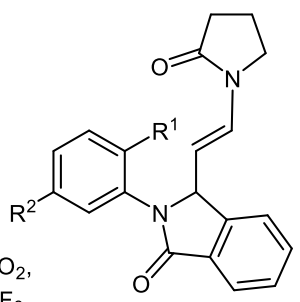

$65,39-66 \%$
Scheme $10(4+2)$ Aza-Diels-Alder reaction and condensation to $\mathrm{N}$-acyliminium ion

Furthermore, this method was readily extended to $\mathrm{N}$-aryl-3hydroxyisoindolinones 63 with an ortho substituent on the $N$ aryl group (Scheme 10B). In sharp contrast with what had previously been observed, when the $N$-aryl has an ortho substituent, the steric hindrance has a deleterious effect on the outcome of the reaction. Indeed, in this particular case, after the condensation of the enamide $\mathbf{6 4}$ on the $N$-acyliminium ion generated from 63, the reaction stopped and afforded non cyclized compounds $\mathbf{6 5}$ in modest yields.

On the basis of previous literature, ${ }^{21}$ the authors suggested a nonconcerted mechanism that starts with the nucleophilic attack of the tertiary enamide on the $N$-acyliminium ion generated from $N$ aryl-3-hydroxyisoindolinones $\mathbf{6 0}$ and 63. The possible cisoid geometry of the intermediate allowing the cyclization afforded isoindoloquinoline derivatives $\mathbf{6 2}$. In contrast, in the case of sterically hindered ortho-substituted $\mathrm{N}$-aryl groups, a $\beta$-proton elimination occurs, leading to the formation of non-cyclized compounds 65.

In 1999, Batey and co-workers examined a Lewis acidpromoted three-component [4+2] cycloaddition to synthesize the alkaloid core structure of martinelline. ${ }^{22}$ The authors described a straightforward lanthanide triflate-catalyzed one-pot reaction of anilines 66 , benzaldehydes 67 , and enecarbamate 68 for the synthesis of hexahydropyrrolo[3,2,c] quinolines 69 in good to excellent yields as a separable endo/exo mixture of diastereoisomers (Scheme 11).

The authors studied solvent effects on the diastereoselectivity of the formation of adduct $\mathbf{6 9}$. They showed that using water as a co-solvent enhanced the formation of the endo adduct (de up to $92 \%$ ), presumably because of the hydrophobic effect favoring a more compact transition state. Unluckily, using water as a cosolvent lessened the yield almost by half.

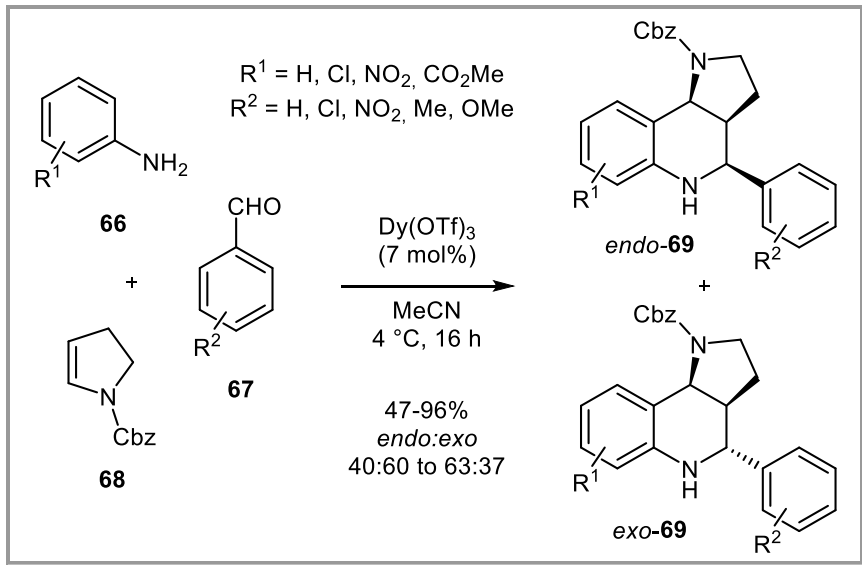

Scheme 11 Three-component [4+2] cycloaddition to hexahydroquinolines

The same year, Stevenson and co-workers reported a similar strategy for the synthesis of pyrroloquinolines. ${ }^{23}$ In the that case, preformed imines $\mathbf{7 0}$ were used - instead of a mixture of aniline and aldehyde - which combined with enamides $\mathbf{7 1}$ undergo [4+2] cycloaddition under Lewis acid catalyzed conditions using $\mathrm{InCl}_{3}$, providing pyrroloquinolines $\mathbf{7 2}$ in modest yields and as an endo:exo mixture (Scheme 12).

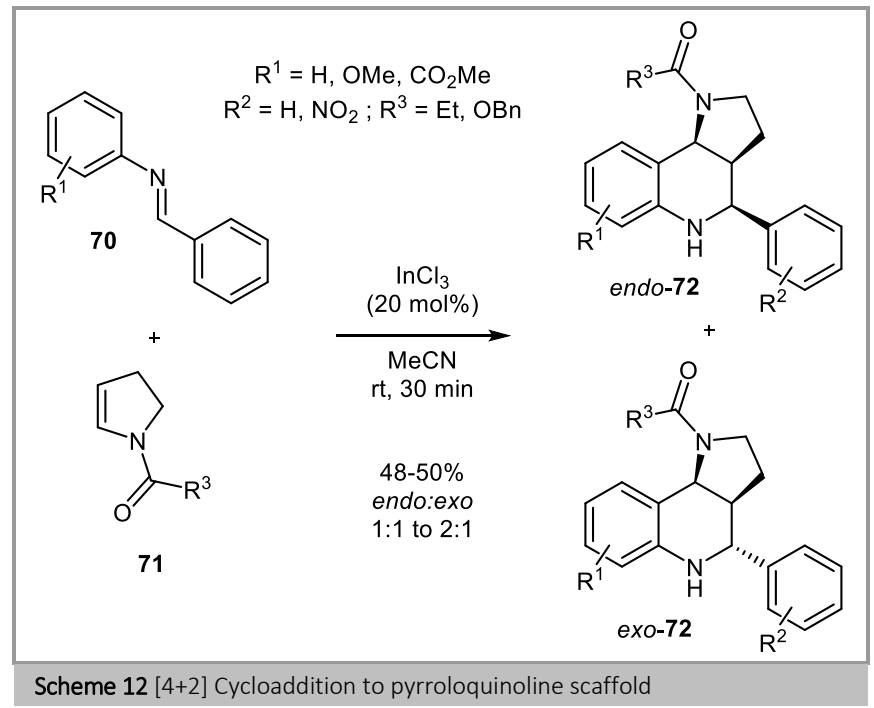




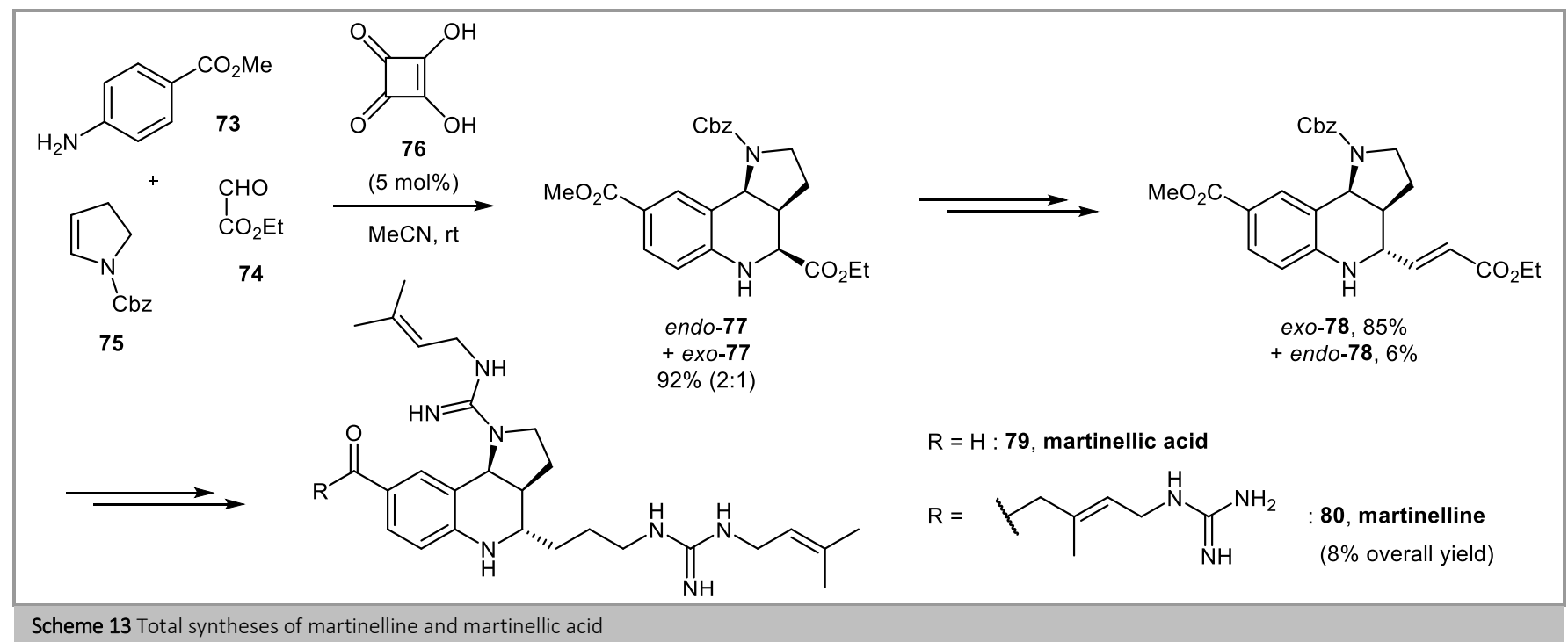

In 2002, Ma and co-workers described their total synthesis of martinelline 80 and martinellic acid 79.24 Based on the previous work of Batey and Stevenson, 22,23 a slightly modified strategy was used for the synthesis of the hexahydropyrroloquinolines core. In this context, the authors investigated the use of squaric acid $\mathbf{7 6}$ as catalyst, and improved the aforementioned one-pot three-component [4+2] cycloaddition to afford cycloadduct $\mathbf{7 3}$ from 4 methoxycarbonylaniline $\mathbf{7 3}$, ethyl glyoxalate $\mathbf{7 4}$ and enecarbamate $\mathbf{7 5}$ (Scheme 13). In this way, the pyrroloquinoline core $\mathbf{7 7}$ was obtained in 92\% yield as an endo:exo (2:1) mixture. Although the exo adduct is useless for further transformations, the authors showed that a Swern oxidation/Wittig olefination sequence led to an unexpected isomerization of the endo adduct into the more thermodynamically stable exo adduct $\mathbf{7 8}$ required to obtain the core structure of martinelline (Scheme 13).

\section{$4 \quad$ Electrocyclizations and cycloisomerizations}

In 2006, Funk and co-workers examined the synthesis of indoles via $6 \pi$-electrocyclization of trienecarbamates. ${ }^{25}$ Trienes $\mathbf{8 1}$ underwent electrocyclic ring closure upon heating at $110{ }^{\circ} \mathrm{C}$ within a few hours to provide a cyclohexadiene intermediate that can be easily oxidized by DDQ in the same pot, thus affording $N$-Boc protected anilines $\mathbf{8 2}$ in good to excellent yields (Scheme 14A). Then, a treatment with TFA allowed the removal of the Boc protection, and a subsequent step using conditions developed by Råileanu and co-workers ${ }^{26}$ enables access to indoles $\mathbf{8 3}$ in good yields via cyclization.

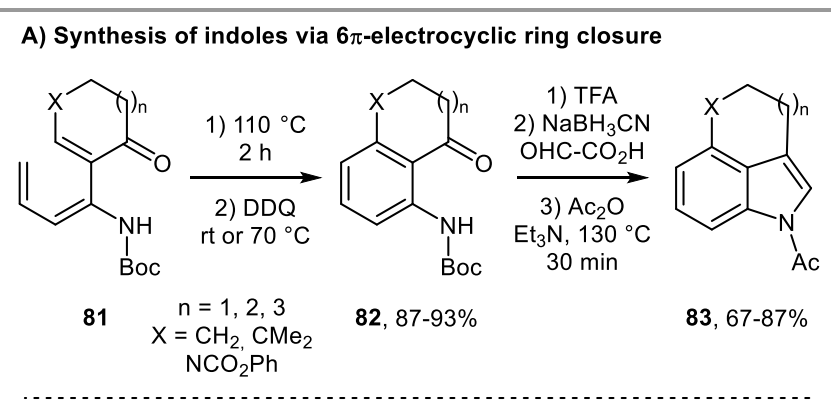

B) Total syntheses of cis-Trikentrin A and cis-Trikentrin B

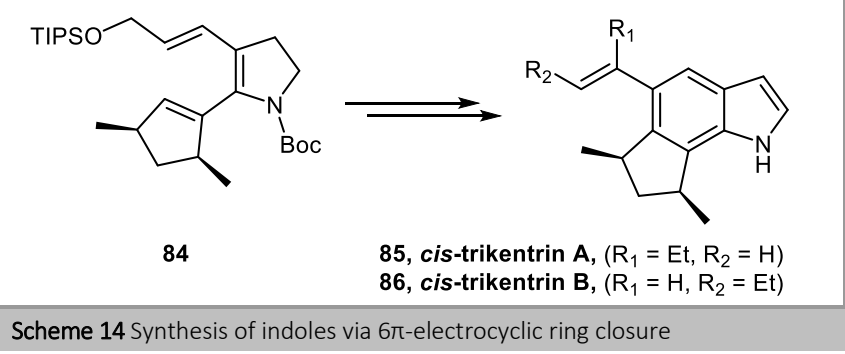

In this way, total syntheses of cis-Trikentrin A 85 and cisTrikentrin B 86 could be achieved in 10 and 12 steps respectively, from commercially available substrate (Scheme 14B). ${ }^{27}$

In the following year, Wang, Yang and co-workers developed a strategy for the synthesis of carbazole derivatives. ${ }^{28}$ Trienes 87 underwent photoinduced oxidative $6 \pi$-electrocyclic ring closure using iodine and UV light to afford carbazoles $\mathbf{8 8}$ in modest to good yields (Scheme 15). 


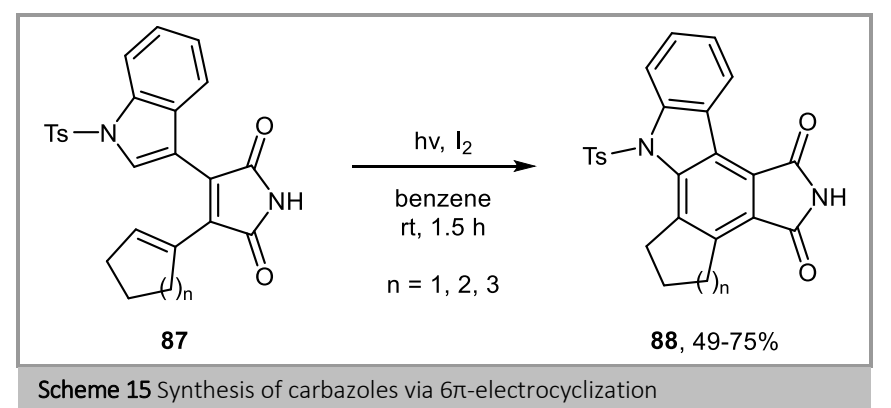

Most recently, Menon and co-workers reported a goldcatalyzed regioselective cascade cycloisomerization reaction of aza-enediynes $\quad \mathbf{8 9}, \quad$ affording substituted dihydrobenzo[f]isoquinoline derivatives $\mathbf{9 0}$ in excellent yields (Scheme 16). ${ }^{29}$ The authors postulated the following reaction mechanism: aza-enediynes $\mathbf{8 9}$ underwent gold-catalyzed propargyl-Claisen rearrangement, providing a $\beta$-allenyl imine $\mathbf{9 1}$. Subsequent tautomerization proceeded via 1,3-hydride shift followed by a $6 \pi$-aza-electrocyclization to yield dihydropyridine 93. The latter underwent gold-catalyzed 6-endo-dig cyclization and proto-deauration to obtain the substituted benzoisoquinoline derivatives 90 (Scheme 16).

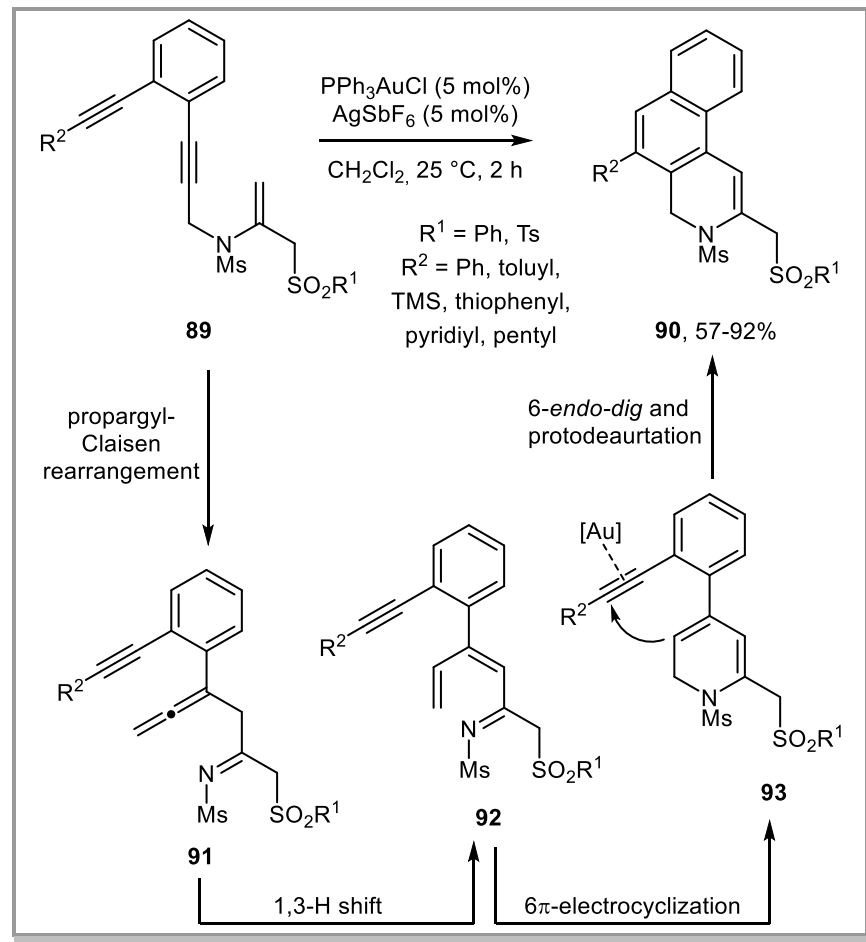

Scheme 16 Gold-catalyzed cycloisomerization reactions of aza-enediynes

\section{$5 \quad$ Sigmatropic Rearrangements}

In 2007, Meyer and co-workers reported an interesting strategy for the stereoselective synthesis of 1,2-amino alcohols that rely on a [2,3]-Wittig rearrangement of enamides derivatives. ${ }^{30}$ Tertiary enamides bearing an amide group 94 were submitted to LiHMDS in THF at $-78^{\circ} \mathrm{C}$ with HMPA as a polar cosolvent; under these conditions, [2,3]-Wittig rearrangement occurred with good diastereoselectivity, affording syn 1,2-amino alcohol 95 in modest to good yields (Scheme 17A). In contrast, tertiary enamides bearing an alkynyl substituent 96 were efficiently converted to 1,2-amino alcohols $\mathbf{9 7}$ upon treatment by LDA in THF at $-78{ }^{\circ} \mathrm{C}$ and with high anti diastereoselectivity (Scheme 17B).

\section{A) [2,3]-Wittig rearrangment of amides}<smiles>[R]N([AsH3-])/C=C/COCC(=O)N1CCCC1</smiles>

94

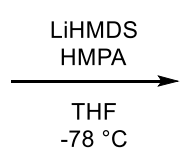

$-78^{\circ} \mathrm{C}$

$\mathrm{R}=\mathrm{Bn}, \mathrm{PMB}, \mathrm{PMP}$, allyl, homoallyl

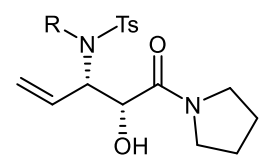

$95,49-77 \%$ syn/anti $90: 10$ to $96: 4$

B) $[2,3]-$ Wittig rearrangment of propargylic ethers<smiles>[R7]N([3H])/C=C\COCC#CF</smiles>

96

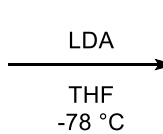

$-78^{\circ} \mathrm{C}$

$\mathrm{R}^{1}=\mathrm{Bn}, \mathrm{PMB}$, allyl, homoallyl $\mathrm{R}^{2}=\mathrm{TMS}, \mathrm{TIPS}$

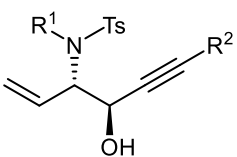

97, $76-93 \%$ anti/syn $92: 8$ to $96: 4$

\section{C) Five-membered ring transitions states}

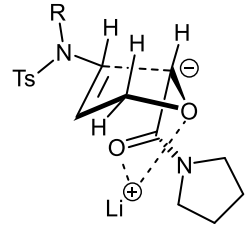

endo-98

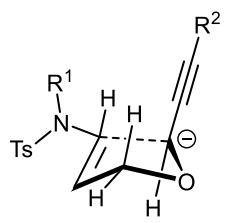

exo-99
Scheme 17 [2,3]-Wittig rearrangement of enamides derivatives

To rationalize the diastereoselectivity observed during these reactions, the authors proposed a five-membered ring transition state model with an envelope conformation (Scheme 17C). In the case of an enamide bearing a $\pi$-acceptor amide group 98, an endo orientation is favored owing to orbital electrostatic interactions, whereas in the case of a $\pi$-donating stabilizing alkynyl group $\mathbf{9 9}$, an exo orientation is preferred, thus explaining the anti/syn diastereoselectivity.

In 2008, Carbery and co-workers developed a method for the synthesis of $\beta$-amino acids that occurs via a [3,3]-IrelandClaisen rearrangement. ${ }^{31}$ Tertiary enamides $\mathbf{1 0 0}$ underwent $[3,3]$-sigmatropic rearrangement upon reaction with LiHMDS and TMSCl at low temperatures to afford $\beta$-amino methyl esters 101 after a subsequent treatment with $\mathrm{TMSCHN}_{2}$ (Scheme 18). The anti diastereoselectivity observed during the reaction is consistent with a preferred antiperiplanar conformation of the six-membered ring chair transition state $\mathbf{1 0 2}$. 


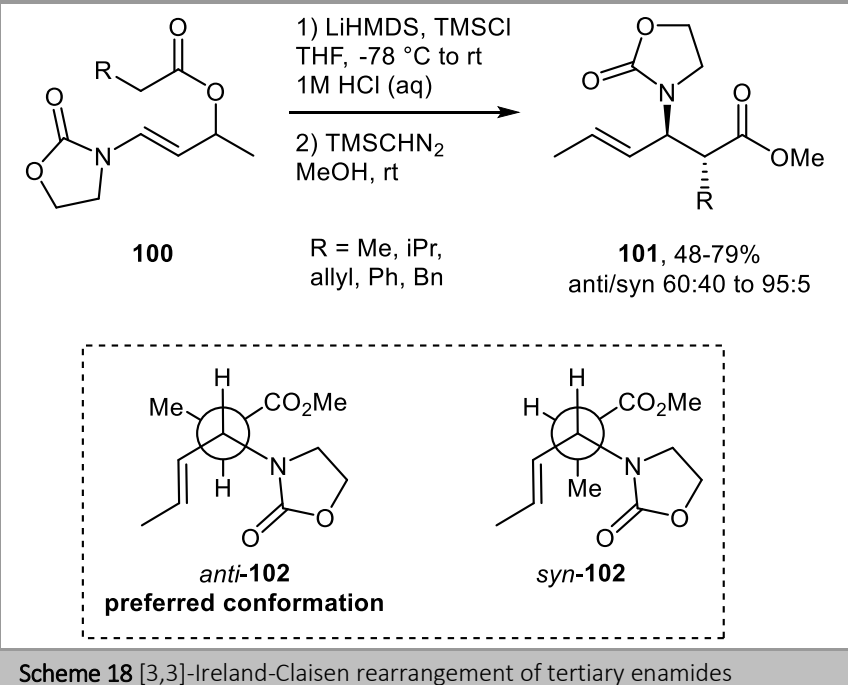

A few years later, Cossy, Meyer, and co-workers thoroughly examined the stereoselectivity issues of [2,3]-Wittig rearrangements and [3,3]-Ireland-Claisen rearrangements. ${ }^{32}$

\section{$6 \quad$ Nucleophilic Additions}

In 2004, Funk and co-workers reported a diastereoselective synthesis of tetrahydropyranones using Prins cyclization between enecarbamates and oxycarbenium ions. ${ }^{33}$ The synthesis was based on the initial formation of an oxycarbenium ion 106 by reaction between the alcohol moiety tethered to an enecarbamate 103 and an aldehyde 104. The enecarbamate moiety underwent nucleophilic addition on the oxycarbenium ion 106, and a subsequent hydrolysis of the generated iminium ion $\mathbf{1 0 7}$ occurred to provide tetrahydropyranones $\mathbf{1 0 5}$ in a diastereoselective fashion and in moderate to good yields (Scheme 19).

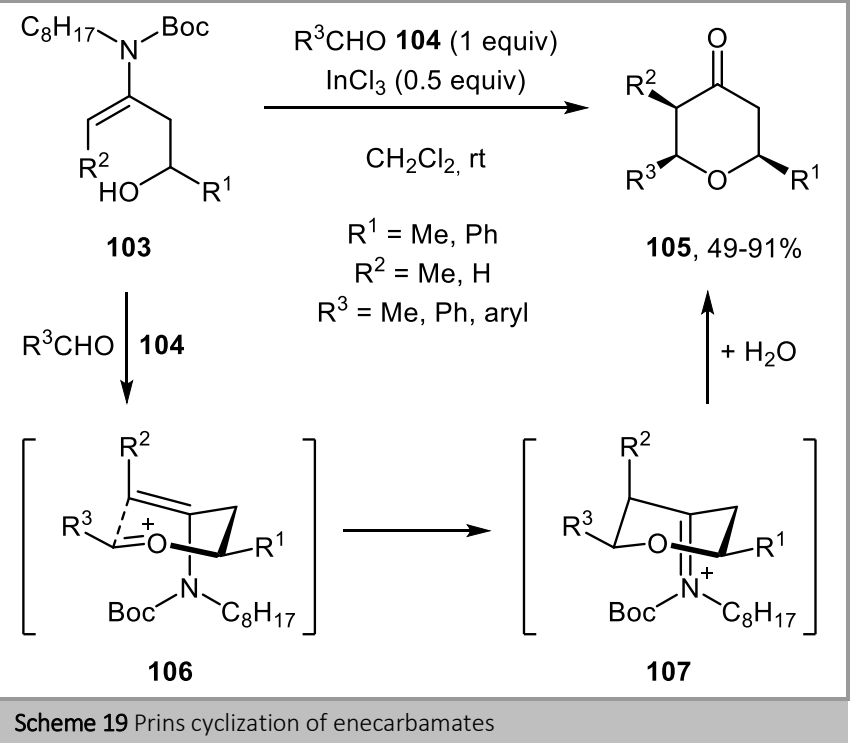

The authors presume that the diastereoselectivity occurs during the cyclization considering a di-equatorial chairlike conformer 106 (Scheme 19).

In 2018, Tong, Wang and co-workers developed an interesting strategy for the divergent synthesis of amino alcohols 109 or pyrroles $\mathbf{1 1 0}$ that relies on the use of different Lewis acid catalysts to tame the reactivity of tertiary enamides tethered to aldehydes 108 (Scheme 20). ${ }^{34}$ Using scandium triflate in 1,4dioxane, tertiary enamides $\mathbf{1 0 8}$ underwent nucleophilic addition to the aldehyde moiety, and hydration of the cyclic iminium intermediate $\mathbf{1 1 2}$ induced ring-opening, affording amino alcohols 109 in moderate to good yields (Scheme 20). By contrast, the aluminum catalyzed reaction proceeded in toluene with molecular sieves to promote the addition of the tertiary enamides 108 onto the aldehyde, and the iminium ion intermediate $\mathbf{1 1 3}$ underwent isomerization to afford tertiary enamide 114. A final dehydration/aromatization step allowed the formation of pyrroles 110 in excellent yields (Scheme 20).

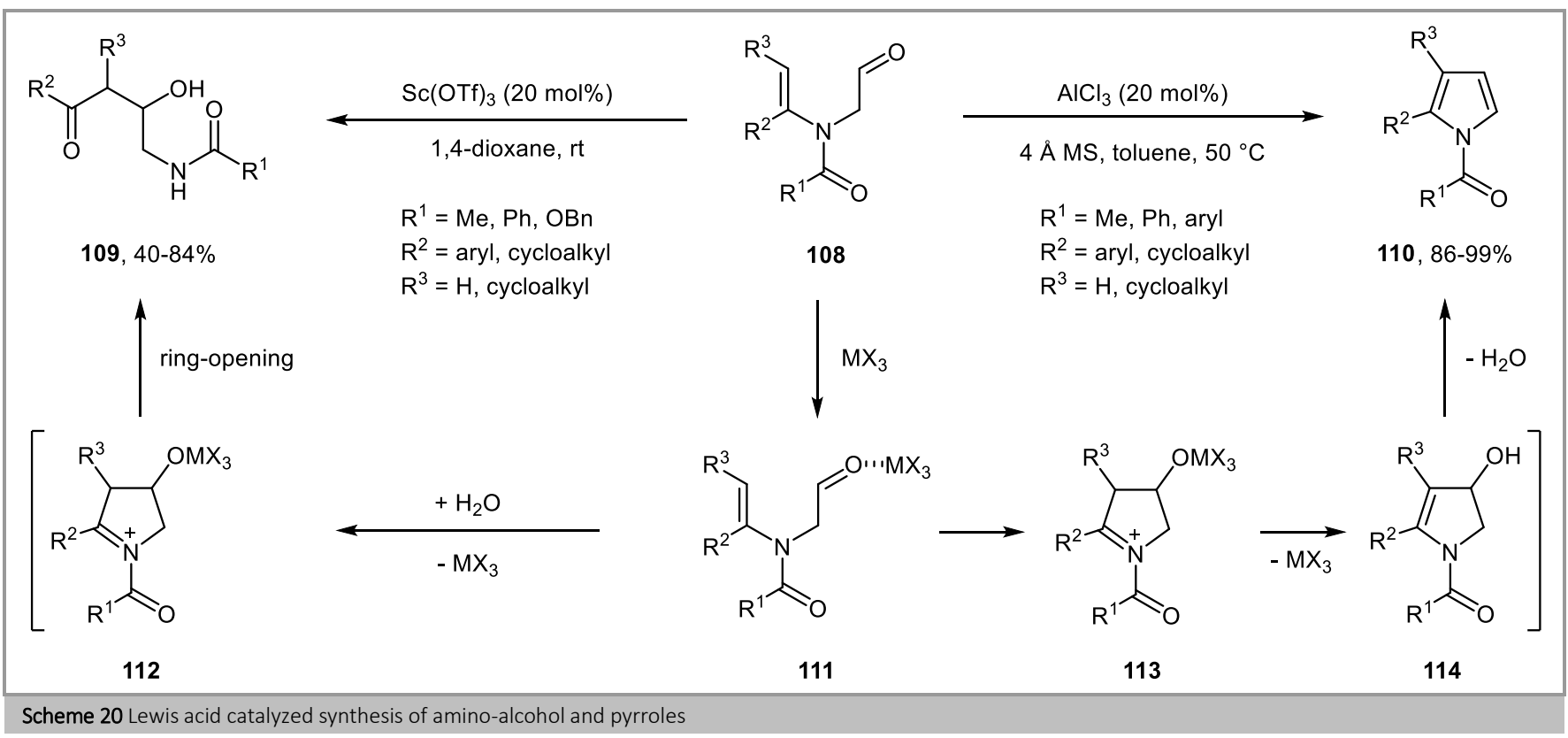


Similarly, another method relying on the intramolecular condensation of tertiary enamides equipped with aldehydes was also established by Wang and co-workers to access fused 7-membered $N$-heterocyclic compounds, notably azepines derivatives. (( REF JOC 2015))

In 2019, Wang and co-workers developed an interesting asymmetric cascade reaction of tertiary enamides 115 leading to the synthesis of complex $N$-heterocyclic compounds 116 possessing a substructure that is highly prevalent in natural bioactive alkaloids (Scheme 21A). ((REF ACIE 2016)) Their work described a tandem reaction starting with a catalytic enantioselective intramolecular nucleophilic addition reaction of tertiary enamides $\mathbf{1 1 5}$ to ketones generating acyliminium ions 117. The latter were intercepted by a tethered electron-rich aryl moiety - in a highly diastereoselective manner - to afford pyrrolo[2,1-a] isoquinoline derivatives 116 in good to excellent yields and with high enantiopurity (Scheme 21A).

A) Tandem reaction for the synthesis of pyrrolo[2,1-a]isoquinoline<smiles>[R][R]C(=C)N(CCc1ccccc1)C(=O)C([R])=O</smiles>

$\mathrm{Cu}(\mathrm{OTf})_{2}(10 \mathrm{~mol} \%)$ Ligand 118 (10 mol\%) $\overrightarrow{\mathrm{CH}_{2} \mathrm{Cl}_{2}, 30^{\circ} \mathrm{C}, 1 \mathrm{~h}}$

$\mathrm{R}^{3}$ 115 $\mathrm{R}^{1}=\mathrm{Ph}$, aryl, $\mathrm{tBu}$
$\mathrm{R}^{2}=\mathrm{Ph}$, aryl $\mathrm{R}^{3}=\mathrm{OMe}$<smiles>[R]c1cccc2c1CCN1C(=O)[C@]([R1])(O)C[C@@]21[R2]</smiles><smiles>[R]CCC1=[N+](CCc2cccc([R])c2)C(=O)[C@@]([R1])([O-])C1</smiles>
intermediate 117

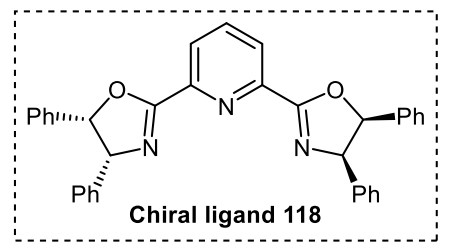

B) Tandem reaction for the synthesis fused $\mathbf{N}$-heterocycles

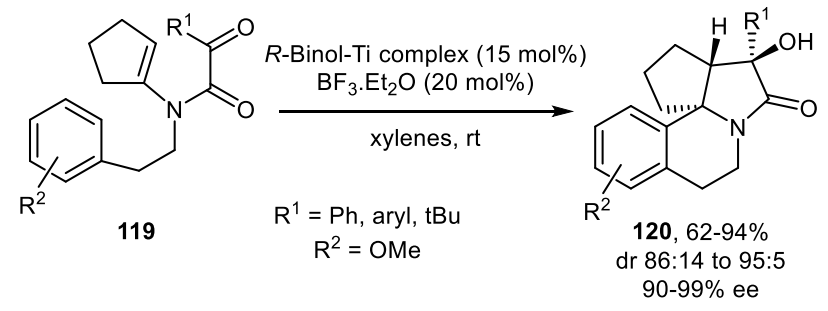

Scheme 21 Catalytic enantioselective tandem reaction

More recently, Wang and co-workers examined a similar strategy - as previously mentioned - for the synthesis of complex fused $N$ heterocycles 120 with contiguous tetrasubstituted stereogenic centers (Scheme 21B). ((REF Chem Eur J 2020)) Tertiary enamides 119 underwent enantioselective intramolecular addition to ketones with subsequent trapping of the resulting acyliminiums ions by electron-rich aryl moieties to provide fused $\mathrm{N}$-heterocyclic products $\mathbf{1 2 0}$ with good yields and high selectivity.

Pursuing their outstanding research on tertiary enamides, Tong, Wang, and co-workers examined the cyclization of tertiary enamides tethered to in situ formed imines using a chiral phosphoric acid (CPA) catalyst. ${ }^{38}$ The aldehyde moiety of the enamides 121 reacted quantitatively with defined amines

(DMP or DHDBA), providing imine-tethered enamides 122, which then underwent intramolecular cyclization, under asymmetric catalysis induced by the CPA catalyst, affording tetrahydropyridines $\mathbf{1 2 3}$ in good to excellent yields (Scheme 22). It is interesting to note that the removal of the $\mathrm{N}$-protecting group can be achieved, ${ }^{38}$ demonstrating the potential of this method for further possible synthetic modifications on the obtained substrates.<smiles>[R17]CCCN(C([R])=C)C([R])=O</smiles>

Scheme 22 Enantioselective synthesis of tetrahydropyridine

In 2018, our group (Andna and co-workers) described a Lewis acid-mediated synthesis of medium-sized diazaheterocycles. ${ }^{39}$ The treatment of tertiary enamides tethered to $\mathrm{N}$ acyl-iminium ion (NAI) precursors $\mathbf{1 2 4}$ with TMSOTf under mild conditions led to the formation of a variety of different diazaheterocycles $\mathbf{1 2 5}$ in moderate to good yields (Scheme 23). A plausible mechanism for the cyclization is outlined in Scheme 23. The process starts with the formation of the NAI 126 under Lewis acid conditions, which is trapped by the tertiary enamide moiety, providing diaza-heterocycles $\mathbf{1 2 5}$ after a final deprotonation to regenerate the enamide.

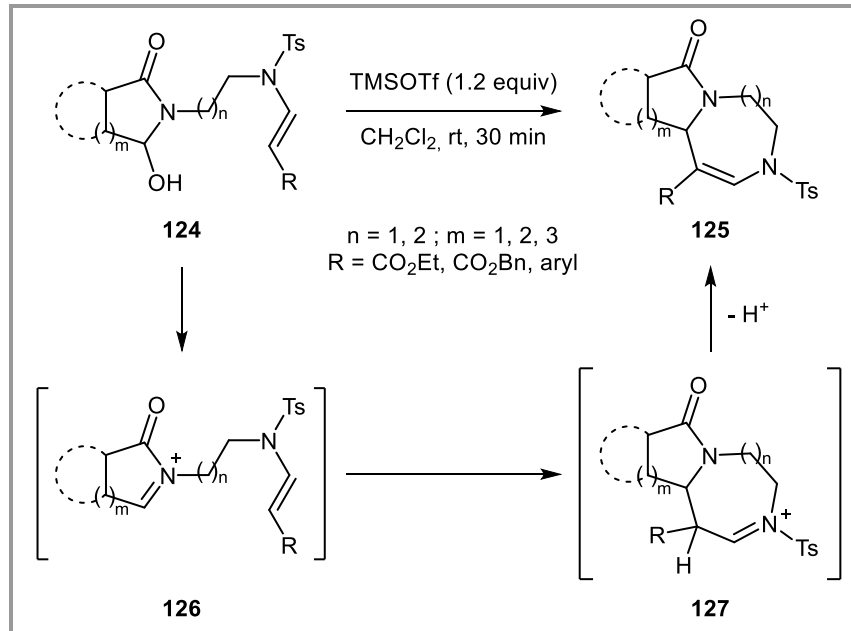

Scheme 23 Intramolecular nucleophilic addition of enamides to $\mathrm{N}$-acyliminium ions 
In 2004, Suga, Yoshida and co-workers developed a diastereoselective three-component coupling reaction for the synthesis of disubstituted pyrrolidines 131.40 This method relies on the "cation pool" method ${ }^{41}$ which consist in generating and accumulating in solution highly reactive carbocations by irreversible electrochemical oxidation. Thus, $N$-carbamates $\mathbf{1 2 8}$ underwent oxidation, affording highly reactive $N$-acyl-iminium ions 132, which further reacted with enecarbamates 129 to provide an iminium intermediate 133, in possible equilibrium with a cyclic form 134. The oxonium intermediate 134 can then be trapped by addition of various nucleophiles $\mathbf{1 3 0}$ to generate disubstituted pyrrolidines $\mathbf{1 3 1}$ in moderate to good yields and with good enantiomeric excess (Scheme 24).

In 2012, a stereoselective route for the synthesis of piperidines was published by Floreancig and co-workers. ${ }^{42}$ Tertiary enamides tethered to a pendent nucleophile $\mathbf{1 3 5}$ underwent intramolecular cyclization, via a $N$-acyl-iminium ion intermediate 138, by reaction with DDQ in nitromethane, affording in only a few minutes piperidines 136,137 in good to excellent yields and diastereomeric ratios (Scheme 25). It is worth noting that the stereocontrol is obtained according to the geometry of the $\mathrm{N}$-acyl-iminium ion intermediate 138.

Later in 2015, Gharpure and co-workers reported the stereoselective synthesis of indolines via alkyne iminium ion cyclization of enesulfonamides. ${ }^{43}$ Tertiary enamides 139 derived from $o$-alkynyl anilines underwent intramolecular cyclization mediated by TMSOTf to afford indolines $\mathbf{1 4 0}$ in moderate to good yields and with good stereocontrol (Scheme 26). The authors presume that the process starts with the generation of an iminium ion 141, which is then intramolecularly trapped by the alkyne moiety, affording a cationic intermediate $\mathbf{1 4 2}$. Hydrolysis of the ketene silyl acetal 142 provided indolines 140 (Scheme 26).

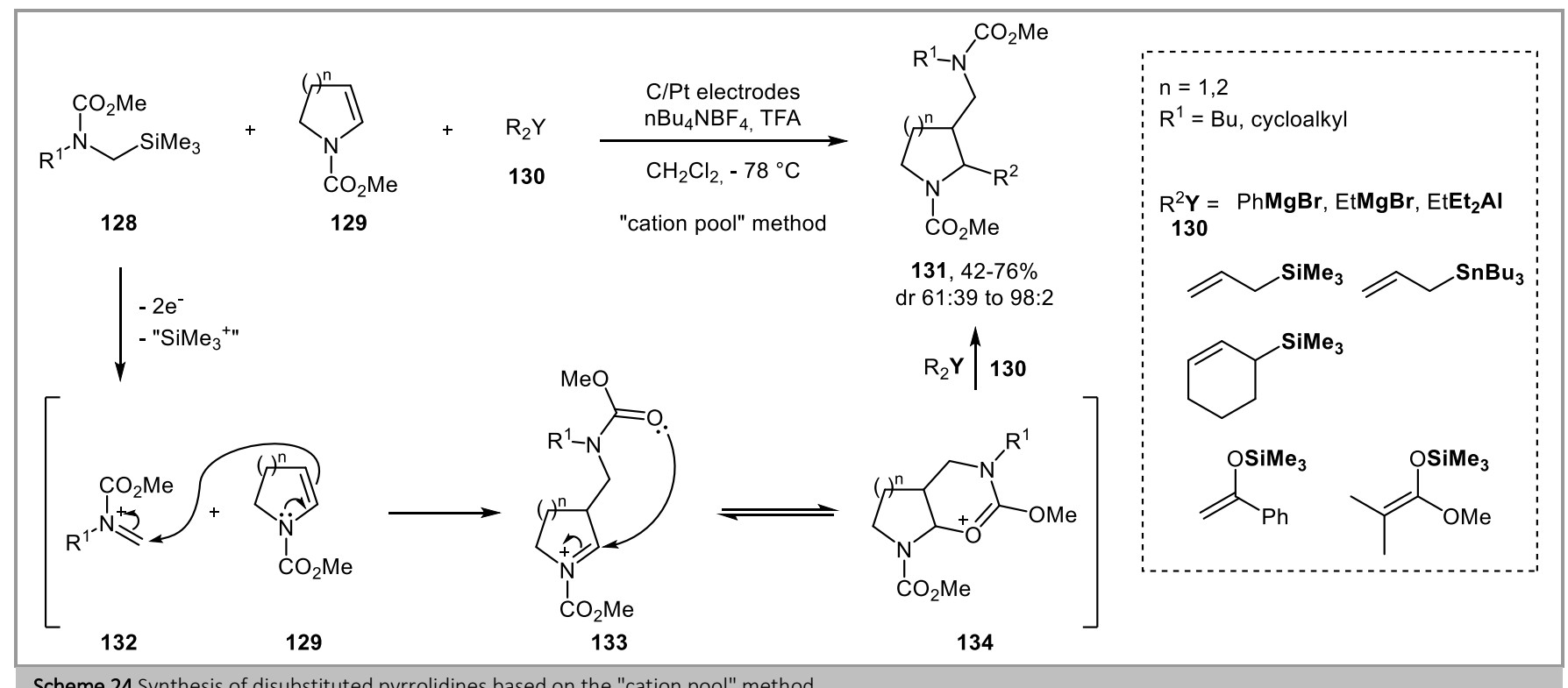

Scheme 24 Synthesis of disubstituted pyrrolidines based on the "cation pool" method 


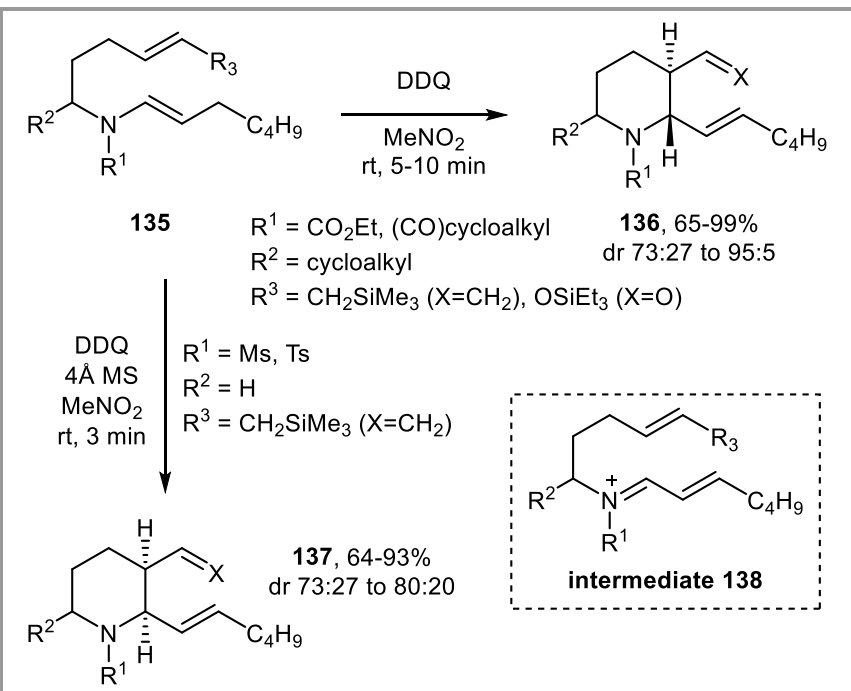

Scheme 25 Stereoselective synthesis of piperidines

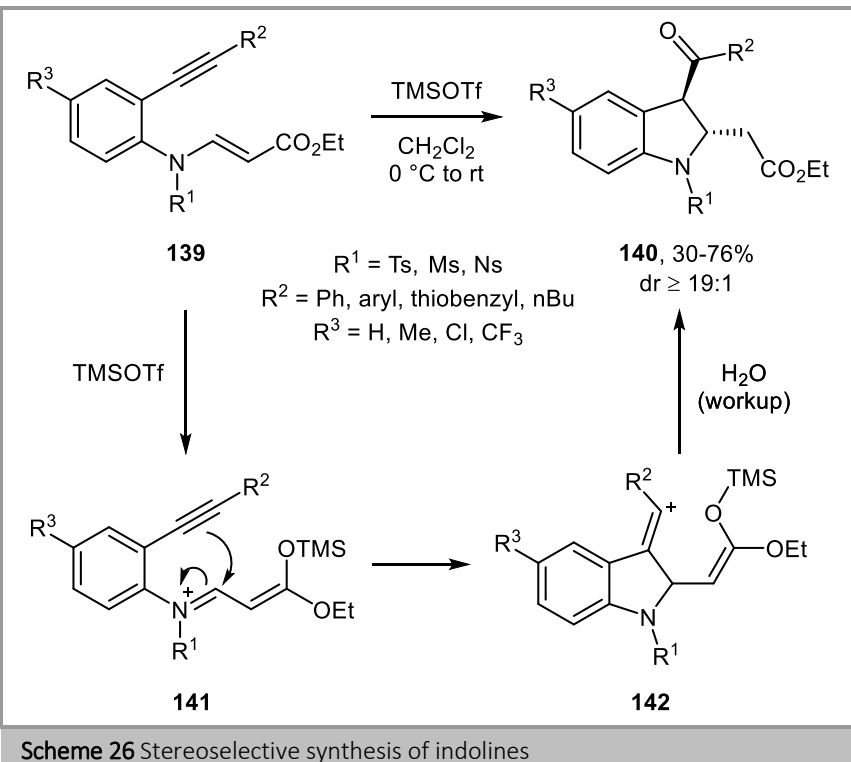

\section{Cross Coupling Reactions}

In 2016, Yang and co-workers published their research on the palladium-catalyzed cross coupling between two different enamides. ${ }^{44}$ Enamides 143 and 144 reacted with $\mathrm{Pd}(\mathrm{OAc})_{2}$ as catalyst in DCE at $110{ }^{\circ} \mathrm{C}$ and afforded heterodimer 145 in moderate to excellent yields. It is interesting to note that the reaction operates with good regioselectivity - only the (Z)heterodimer 145 was obtained, probably because of steric effects (Scheme 27). The chemoselectivity might be rationalized by the fact that the tertiary enamide $\mathbf{1 4 3}$ acts as an electrophile because of its preferred coordination to the palladium catalyst, while secondary enamides 144 behave as nucleophiles. A plausible mechanism was suggested (Scheme 27). The authors suggest that the process starts with the coordination of Pd-catalyst to the tertiary enamide 143. Nucleophilic addition of the secondary enamide 144 operates on the palladium-activated intermediate 146 to afford iminium 147. Finally, imine-enamine tautomerization occurs to provide enamide $\mathbf{1 4 8}$, and subsequent protonation furnishes heterodimer 145.

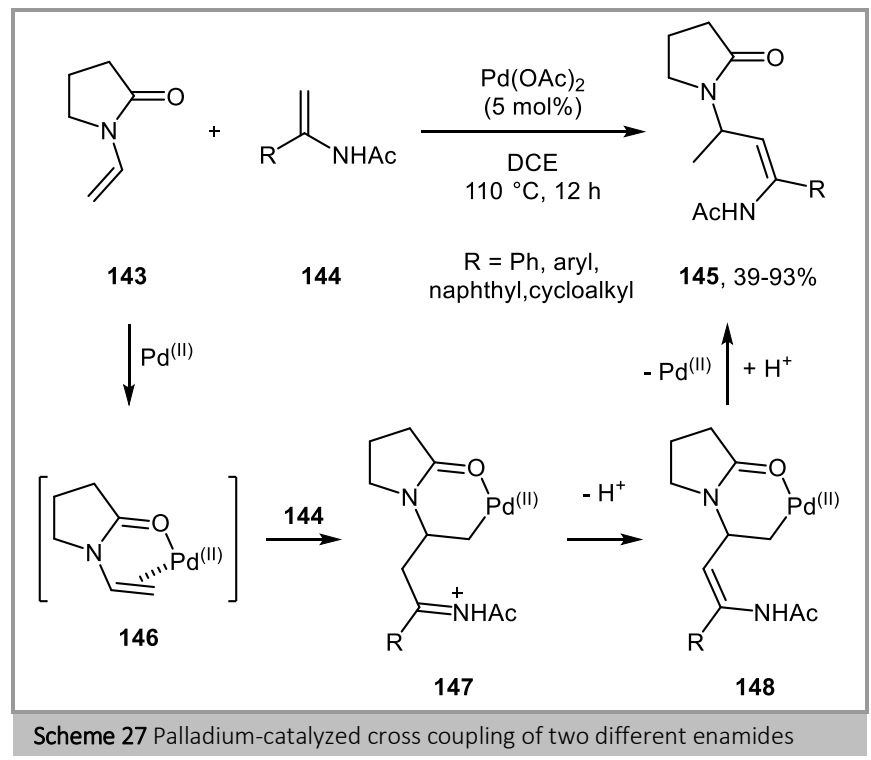

Recently, Tong, Wang and co-workers reported a palladium-catalyzed dehydrogenative intramolecular cross coupling reaction between tertiary enamides and arenes. ${ }^{45}$ Tertiary enamides tethered to an arene moiety 149 underwent intramolecular arylation in DMSO with catalytic amounts of $\mathrm{Pd}(\mathrm{OAc})_{2}$ and $\mathrm{Cu}(\mathrm{OAc})_{2}$ under an oxygen atmosphere to provide cyclized products $\mathbf{1 5 0}$ in modest to good yields (Scheme 28A). The authors suggested that the mechanism goes through an 8membered palladacycle intermediate, which subsequently undergoes reductive elimination, affording desired fused heterocycle 150. The $\mathrm{Cu}(\mathrm{II})$ co-catalyst serves to regenerate $\mathrm{Pd}(\mathrm{II})$ via an oxidative process. To highlight the synthetic utility of this method, the authors developed total syntheses of natural alkaloids 151, 152, and 153 (Scheme 28B).

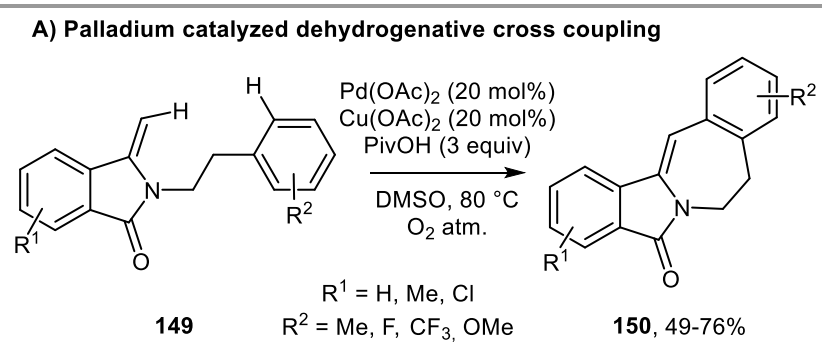

B) Total syntheses of natural products<smiles>[X]C1([X])c2c(ccc(OC)c2O)C2Cc3cc4c(cc3CCN21)OCO4</smiles>

151, $X, X=0$, lennoxamine, $33 \%$ $152, X, X=H$, chilenamine, $31 \%$<smiles>COc1cc2c(cc1OC)C(=O)C1(NC(=O)c3ccc(OC)c(OC)c3C1=O)C(=O)C2</smiles>

153, palmanine, $21 \%$ 
Most recently, several approaches involving the alkylation of tertiary enamides have been developed by Zhao, Loh and coworkers. In a first paper, the authors examined the photoredox-catalyzed alkylation of tertiary enamides via a decarboxylative cross coupling reaction. ${ }^{46}$ Enamides $\mathbf{1 5 4}$ underwent $\beta$-alkylation through decarboxylative cross coupling of $N$-hydroxyphthalimide esters (NHP) 155 using a photoredox iridium catalyst under blue light irradiation to yield alkylated enamides 156 (Scheme 29A). A plausible mechanism for the photoredox-catalyzed alkylation is outlined in Scheme 29B. The authors suggested that the process starts with the excitation of the iridium photocatalyst $\left[\operatorname{Ir}(\mathrm{ppy})_{3}\right]$ to $\left[\operatorname{Ir}(\mathrm{ppy})_{3}{ }^{*}\right]$ under blue LED irradiation. Subsequently, a single electron transfer between $\left[\operatorname{Ir}(\text { ppy })_{3}{ }^{*}\right]$ and the NHP ester $\mathbf{1 5 7}$ occurs to generate radical anion 158, which undergoes decarboxylation to provide alkyl radical 159. This radical is trapped by enamide 160 to produce a tertiary radical $\mathbf{1 6 1}$, which is oxidized by the photocatalyst $\left[\operatorname{Ir}\left(\mathrm{ppy}_{\mathrm{z}^{+}} \mathrm{s}^{+}\right.\right.$to provide intermediates $\mathbf{1 6 2}$ (in equilibrium with iminium ion 163). Lastly, deprotonation of theses previous intermediates affords alkylated tertiary enamides 164 with a stereoselectivity in favor of $(E)$-configured enamides, which can be explained by steric effects.

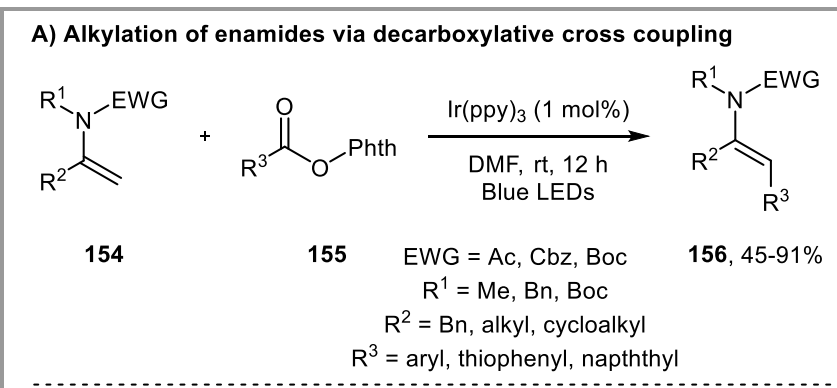

B) Proposed mechanism

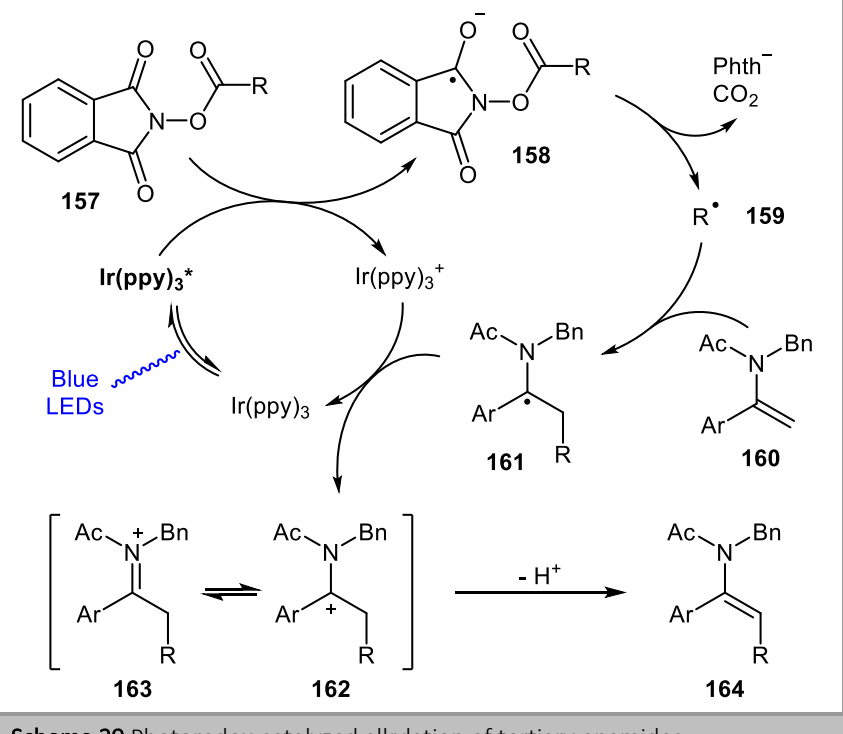

Scheme 29 Photoredox-catalyzed alkylation of tertiary enamides

In addition to their previous results, the same authors reported a similar stereoselective alkylation reaction of enamides via decarboxylative cross coupling using carboxylic acids. ${ }^{47}$ The alkylation of tertiary enamides 165 with carboxylic acids 166 proceeds smoothly using a catalytic amount of silver carbonate in combination with potassium persulfate and sodium bicarbonate to afford exclusively $(E)$-configured alkylated enamides 167 in moderate to good yields (Scheme 30).

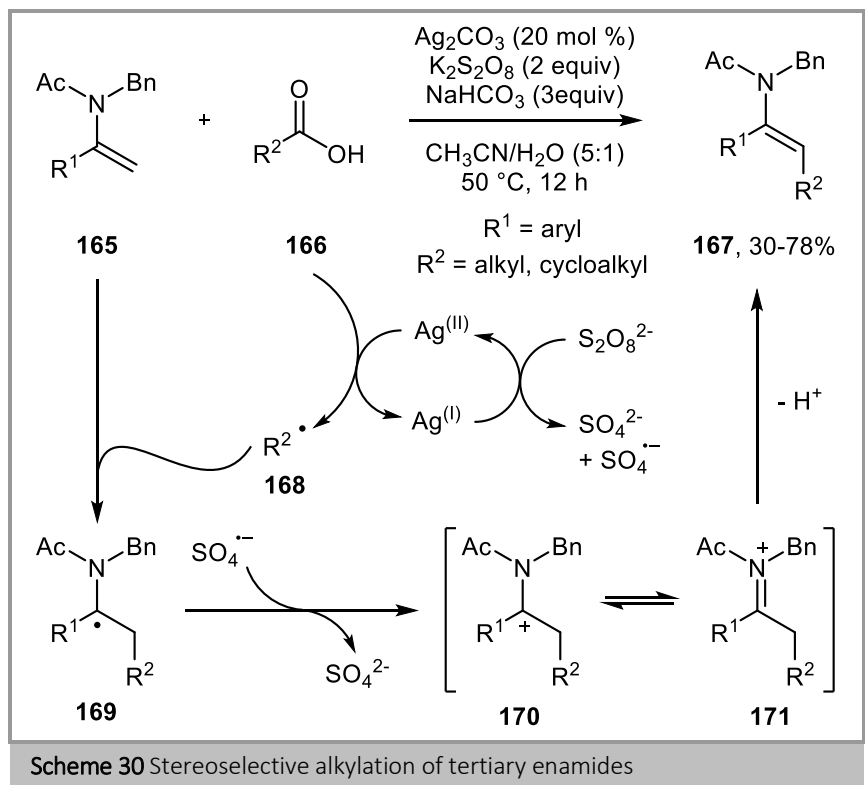

On the basis of additional experiments, the authors suggested the mechanism shown in Scheme 30. First, the $\mathrm{Ag}(\mathrm{I})$ catalyst is oxidized to $\mathrm{Ag}(\mathrm{II})$ by the persulfate anion, which induces oxidative decarboxylation of $\mathbf{1 6 6}$ to generate alkyl radical 168 . Addition of the latter to enamides 165 provides a radical intermediate $\mathbf{1 6 9}$, which is oxidized by sulfate radical anion to generate cationic intermediate $\mathbf{1 7 0}$ (in equilibrium with iminium ion 171). Ultimately, deprotonation of the iminium ion 172 occurs to give alkylated enamides 167.

\section{Tertiary Enamide-assisted Reactions}

An unprecedented method for the synthesis of $\xi$ Clausenamide through tertiary enamide assisted 8-endo-epoxyarene cyclization was reported by Wang and co-workers. ${ }^{48}$ The tertiary enamide tethered to an epoxide moiety 172 reacted smoothly under acidic conditions to afford $\xi$-Clausenamide $\mathbf{1 7 3}$ via addition of the benzene ring to the activated epoxide (Scheme 31). 


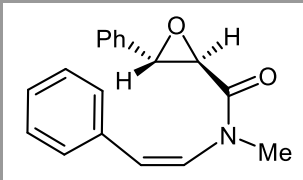

172<smiles>C[P+]</smiles>

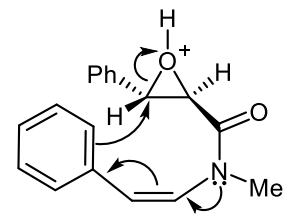

174
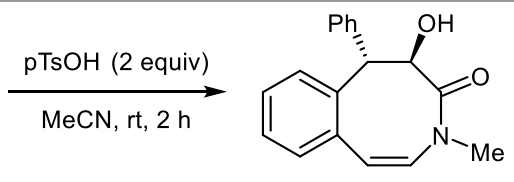

$173,86 \%$ $\xi$-Clausenamide $\uparrow-\mathrm{H}^{+}$ 8-endo-epoxy-arene cyclization

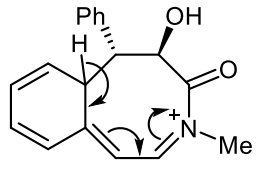

175
Scheme 31 Synthesis of $\xi$-Clausenamide via 8-endo-epoxy-arene cyclization
This unique reactivity stems from synergistic electronic and steric effects: the conjugation of the enamide with the benzene ring and the delocalization of the enamide electrons into the benzene ring combined to afford a spatially propitious folded conformation of the substrate $\mathbf{1 7 4}$ to guide the reaction exclusively in favor of the 8-endo-epoxy-arene cyclization.

Most recently, our group (Beltran and co-workers) reported a highly diastereoselective domino reaction involving the above mentioned delocalization of the tertiary enamide electrons into a benzene ring. ${ }^{49}$ Depending to the choice of the Lewis acid, the amount of allyltrimethylsilane, and the reaction conditions, the authors showed that the reactivity of spiroenesulfonamides $\mathbf{1 7 6}$ could be tuned to obtain either tetracyclic structures 177 or pentacyclic structures 178 in moderate to good yields with the simultaneous creation of four new welldefined stereogenic centers (Scheme 32). 


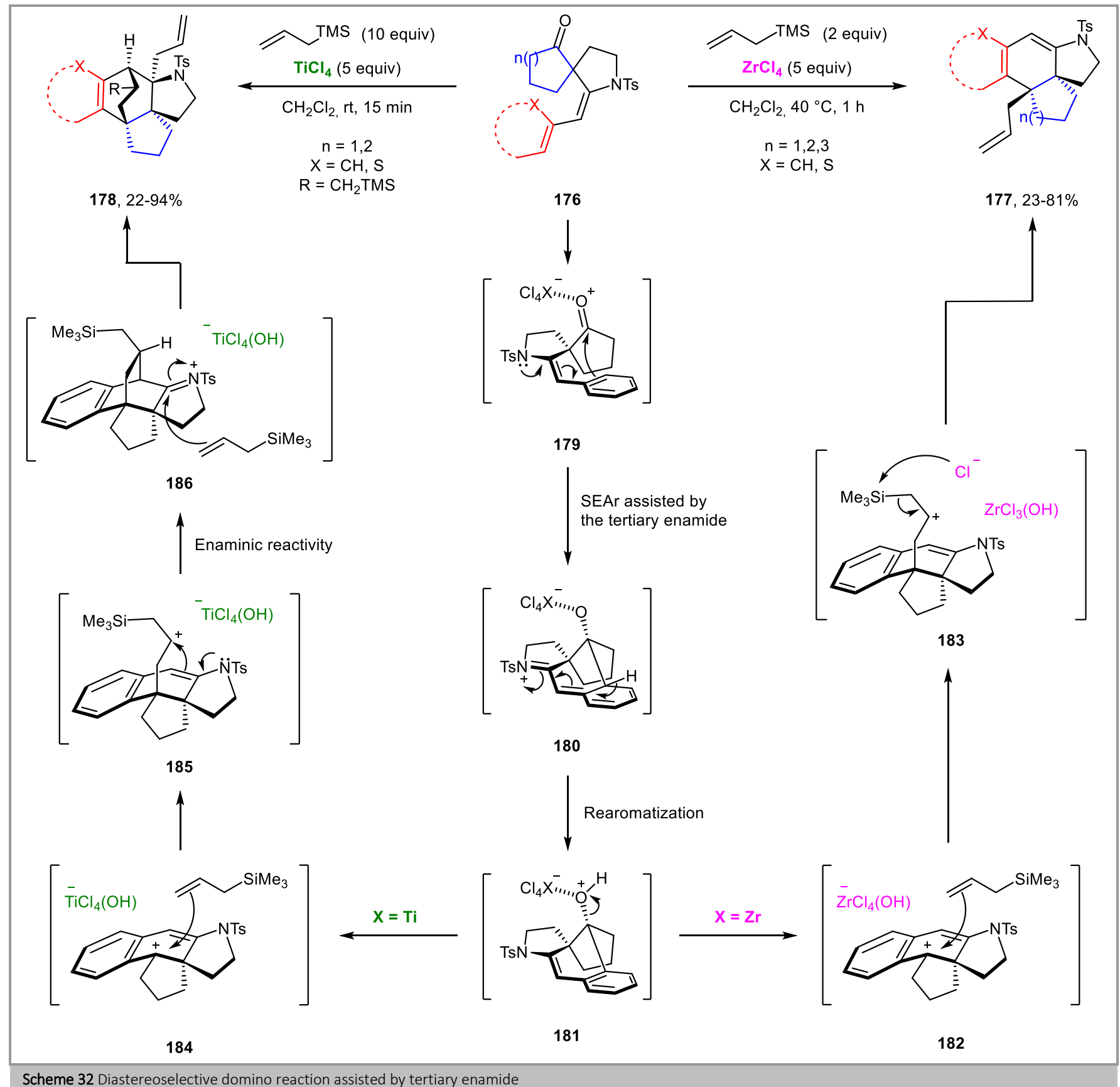

Based on the foregoing results, a plausible mechanism was suggested by the authors (Scheme 32). The process would appear to start with the intramolecular electrophilic aromatic substitution assisted by the tertiary enamide to the activated ketone $\mathbf{1 7 9}$, affording an iminium intermediate $\mathbf{1 8 0}$, which is then rearomatized to regenerate the enamide 181. From this point, two different pathways could be considered, depending on the Lewis acid employed. When zirconium chloride is used: the ionization of the alkoxide 181 leads to a carbocation 182, which can be trapped by the allyltrimethylsilane, affording intermediate 183. Subsequent $\beta$-silyl elimination provides the tetracyclic structure 177. In the case of titanium tetrachloride, a similar process transpires, i.e. formation of a carbocation intermediate 184, which could be trapped by allyltrimethylsilane. The new carbocation 185 thus generated is trapped by the tertiary enamide within the tetracyclic core, affording iminium intermediate 186. The latter can then be trapped by a second molecule of allyltrimethylsilane to yield pentacyclic structure 178 after $\beta$-silyl elimination.

\section{Conclusion and Perspectives}

This short review has summarized methods for the synthesis of diverse functionalized nitrogen-containing heterocycles from simple and easily accessible substrates exploiting the enaminic reactivity of tertiary enamides,. Over the years, tertiary enamides have also proved to be efficient and versatile compounds to access various natural products with high levels of regio- and enantioselectivity. 
However, among the existing methods, few are applicable to a large scope of substrates. Moreover, the use of nonenvironmentally-friendly reagents generating toxic waste and the necessity for harsh conditions set limits on their application in a society focused on sustainable chemistry.

It becomes clear that new syntheses involving tertiary enamides, will in the near future be developed by the scientific community. Owing to their tremendous potential, ready availability, and great stability, the development of new transformations from tertiary enamides is worth pursuing

\section{Acknowledgment}

Dr L. Andna is warmly thanked for her contribution to this short review and to the group's research on tertiary enamides.

\section{References}

(1) (a) Stork, G.; Terrell, R.; Szmuszkovicz, J. J. Am. Chem. Soc. 1954, 76, 2029. (b) Stork, G.; Landesman, H. K. J. Am. Chem. Soc. 1956, 78, 5128. (c) Stork, G.; Landesman, H. K. J. Am. Chem. Soc. 1956, 78, 5129. (d) Stork, G.; Brizzolara, A.; Landesman, H.; Szmuszkovicz, J.; Terrell, R. J. Am. Chem. Soc. 1963, 85, 207.

(2) Gigant, N.; Chausset-Boissarie, L.; Gillaizeau, I. Chem. Eur. J. 2014 $20,7548$.

(3) Wang, M.-X. Chem. Commun. 2015, 51, 6039.

(4) Cai, X.; Yang, M.; Guo, H. Curr. Org. Synth. 2019, 16, 70.

(5) de Faria, A. R.; Matos, C. R. R.; Correia, C. R. D. Tetrahedron Lett. 1993, 34, 27.

(6) Correia, C. R. D.; de Faria, A. R.; Carvalho, E. S. Tetrahedron Lett. 1995, 36, 5109.

(7) Miranda, P. C. M. L.; Correia, C. R. D. Tetrahedron Lett. 1999, 40, 7735.

(8) Neyyappadath, R.; Greenhalgh, M.; Cordes, D.; Slawin, A.; Smith, A. Eur. J. Org. Chem. 2019, 5169.

(9) Himeshima, Y.; Sonada, T.; Kobayashi, H. Chem. Lett. 1983, 1211

(10) Feltenberger, J. B.; Hayashi, R.; Tang, Y.; Babiash, E. S. C.; Hsung, R. P. Org. Lett. 2009, 11, 3666.

(11) Ma, Z.-X.; Feltenberger, J. B.; Hsung, R. P. Org. Lett. 2012, 14, 2742.

(12) de Nanteuil, F.; Waser, J. Angew. Chem. Int. Ed. 2013, 52, 9009.

(13) Bugarin, A.; Jones, K. D.; Connell, B. T. Chem. Commun. 2010, 46, 1715.

(14) Wei, S.; Yin, L.; Wang, S. R.; Tang, Y. Org. Lett. 2019, 21, 1458.

(15) (a) Bach, T.; Schröder, J. Liebigs Ann./Recueil 1997, 2265. (b) Bach, T. Angew. Chem. Int. Ed. Engl. 1996, 35, 884. (c) Bach, T. Schröder, J.; Brandl, T.; Hecht, J.; Harms, K. Tetrahedron 1998, 54, 4507.

(16) Bach, T.; Schröder, J. Synthesis 2001, 8, 1117.

(17) Elliot, L. D.; Booker-Milburn, K. I. Org. Lett. 2019, 21, 1463.

(18) Huang, Y.; Iwama, T.; Rawal, V. H. J. Am. Chem. Soc. 2000, 122, 7843.

(19) Sarkar, N.; Banerjee, A.; Nelson, S. G. J. Am. Chem. Soc. 2008, 130, 9222.

(20) Jha, A.; Chou, T.-Y.; AlJaroudi, Z.; Ellis, B. D.; Cameron, T. S. Beilstein J. Org. Chem. 2014, 10, 848.

(21) Zhang, W.; Zheng, A.; Liu, Z.; Yang, L.; Liu, Z. Tetrahedron Lett. 2005, 46, 5691.

(22) Batey, R. A.; Simoncic, P. D.; Lin, D.; Smyj, R. P.; Lough, A. J. Chem. Commun. 1999, 651.

(23) Hadden, M.; Stevenson, P. J. Tetrahedron Lett. 1999, 40, 1215.

(24) Xia, C.; Heng, L.; Ma, D. Tetrahedron Lett. 2002, 43, 9405.

(25) Greshock, T. J.; Funk, R. L. J. Am. Chem. Soc. 2006, 128, 4946.

(26) Tighineanu, E.; Chiraleu, F. Råileanu, D. Tetrahedron 1980, 36, 1385.

(27) Huntley, R. J.; Funk, R. L. Org. Lett. 2006, 8, 3403.

(28) Li, Y.; Zou, H.; Gong, J.; Xiang, J.; Luo, T.; Quan, J.; Wang, G.; Yang, Z. Org. Lett. 2007, 9, 4057.
(29) Undeela, S.; Chandra, R.; Nanubolu, J. B.; Menon, R. S. Org. Biomol. Chem. 2019, 17, 369.

(30) Barbazanges, M.; Meyer, C.; Cossy, J. Org. Lett. 2007, 9, 3245.

(31) Ylioja, P. M.; Mosley, A. D.; Charlot, C. E.; Carbery, D. R. Tetrahedron Lett. 2008, 49, 1111.

(32) Barbazanges, M.; Meyer, C.; Cossy, J.; Turner, P. Chem. Eur. J. 2011, 17,4480 .

(33) Cossey, K. N.; Funk, R. L. J. Am. Chem. Soc. 2004, 126, 12216.

(34) Xu, X.-M.; Lei, C.-H.; Tong, S.; Zhu, J.; Wang, M.-X. Org. Chem. Front 2018, 5, 3138.

(35) Zhu, W.; Zhao, L.; Wang, M.-X. J. Org. Chem. 2015, 80, 12047.

(36) Xu, X.-M.; Zhao, L.; Zhu, J.; Wang, M.-X. Angew. Chem. Int. Ed. 2016 $55,3799$.

(37) Zhen, L.; Tong, S.; Zhu, J.; Wang, M.-X. Chem. Eur. J. 2020, 26, 401.

(38) Tong, S.; Wang, M.-X. Synlett, 2018, 30, 483.

(39) Andna, L.; Miesch, L. Org. Lett. 2018, 20, 3430.

(40) Suga, S.; Nishida, T.; Yamada, D.; Nagaki, A.; Yoshida, J;-i. J. Am. Chem. Soc. 2004, 126, 14338.

(41) Yoshida, J.-i.; Suga, S. Chem. Eur. J. 2002, 8, 2651.

(42) Brizgys, G. J.; Jung, H. H.; Floreancig, P. E. Chem. Sci. 2012, 3, 438.

(43) Gharpure, S. J.; Prasath, V.; Kumar, V. Chem. Commun. 2015, 51, 13623.

(44) Liu, H.-M.; Lu, W.; Luo, C.-P.; Yang, L. Tetrahedron Lett. 2016, 57, 4243.

(45) Zhu, W.; Tong, S.; Zhu, J.; Wang, M.-X. J. Org. Chem. 2019, 84, 2870.

(46) Guo, J.-Y.; Zhang, Z.-Y.; Guan, T.; Mao, L.-W.; Ban, Q.; Zhao, K.; Loh, T.-P. Chem. Sci. 2019, 10, 8792.

(47) Guo, J.-Y.; Guan, T.; Tao, J.-Y.; Zhao, K.; Loh, T.-P. Org. Lett. 2019, 21 8395.

(48) (a) Yang, L.; Deng, G.; Wang, D.-X.; Huang, Z.-T.; Zhu, J.-P.; Wang, M.X. Org. Lett. 2007, 9, 1387. (b) Yang, L.; Wang, D.-X.; Zheng, Q.-Y.; Pan, J.; Huang, Z.-T.; Wang, M.-X. Org. Biomol. Chem. 2009, 7, 2628.

(49) Beltran, F.; Miesch, L. Org. Lett. 2019, 21, 1569. 


\section{Biosketches}

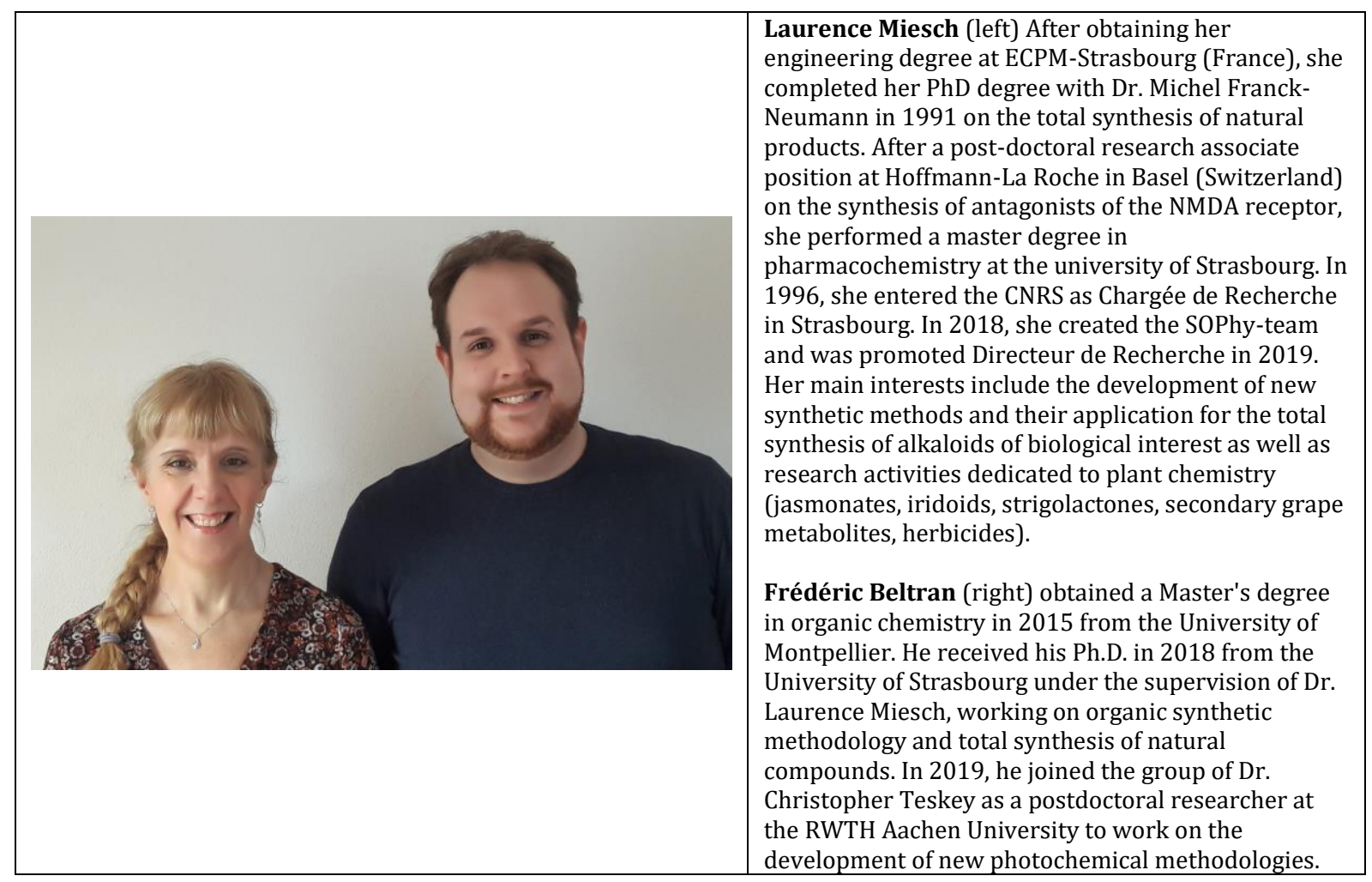

